\title{
Integrated Carbon Sequestration-Geothermal Heat Recovery: Performance Comparison Between Open and Close Systems
}

\author{
Masoud Babaei ${ }^{1}$ iD
}

Received: 12 October 2017 / Accepted: 15 March 2018 / Published online: 27 March 2018

(C) The Author(s) 2018

\begin{abstract}
In this paper, the lateral boundaries for a theoretical homogeneous, isotropic, horizontal, 3-dimensional sedimentary hot aquifer were prescribed by either unhindered open to fluid and heat flow, or compartmentalised fully close boundary conditions. $\mathrm{CO}_{2}$ injection was administered through three well patterns of varying well spacing and numbers: $3 \times 3(5$ injection wells and 4 production wells, $750-\mathrm{m}$ well spacing), $5 \times 5$ (13 injection wells and 12 production wells, 500-m well spacing), and $7 \times 7$ (25 injection wells and 24 production wells, 375-m well spacing). To assess the effects of boundary conditions and well spacing on a combined carbon sequestration-geothermal heat recovery process, number of output metrics such as net cumulative $\mathrm{CO}_{2}$ stored, volumetric storage efficiency, geothermal heat recovery and pressure build-up were quantified in 54 simulation runs. Based on the assumption made and conditions that the simulation, it was shown that for a typical and more common fewer well number cases, the open versus close boundaries have critical role in determining the effectiveness of operation. (a) Open boundary conditions may counter-intuitively lead to heat recovery relative deficiencies if the pressure gradient stays largely towards the outside of the system (pressure of system > pressure of surrounding). This, however, will benefit $\mathrm{CO}_{2}$ injectivity and storage efficiency by providing escape paths for fluids $\left(\mathrm{CO}_{2}\right.$ and brine). (b) Close boundary conditions will universally be beneficial for fluid and heat production purposes; however, the excessive pressure build-up can significantly affect the operation duration length. For economically unjustifiable cases with high number of wells, the effects of boundary conditions were shown to be reduced by effective fluid extraction from the medium, thereby enhancing the geothermal heat recovery and avoiding pressure build-up. The research delineated no significant effect of boundary conditions on salt precipitation.
\end{abstract}

Keywords Carbon sequestration in geothermal aquifers · Geothermal heat recovery · Open and close boundary conditions $\cdot \mathrm{CO}_{2}$-plume geothermal $\cdot \mathrm{CO}_{2}$ storage efficiency $\cdot$ Thermal numerical simulation

Masoud Babaei

masoud.babaei@manchester.ac.uk

1 School of Chemical Engineering and Analytical Science, The University of Manchester, Manchester, UK 


\section{Introduction}

Since 2000, a compelling body of research has been dedicated to numerically evidence the advantages and efficiency of using $\mathrm{CO}_{2}$, alternative to water, as heat transmission fluid for geothermal energy recovery from enhanced geothermal systems (EGS) where the permeability of the underground source is enhanced by hydrofracturing (Brown 2000; Fouillac et al. 2004; Pruess and Azaroual 2006; Atrens et al. 2008; Xu et al. 2015b). It has been reasoned that $\mathrm{CO}_{2}$ has lower viscosity than water and has a thermosyphon effect, which reduces the parasitic power consumption of the working-fluid recirculation system (Buscheck et al. 2012a). Additionally, under favourable conditions for storage, injected $\mathrm{CO}_{2}$ is entrapped in the systems, which helps the economy of the operations by reducing carbon footprint, and as a long-term objective, helps reduce $\mathrm{CO}_{2}$ emission to atmosphere. Nevertheless, if $\mathrm{CO}_{2}$ is being utilised as a transmission fluid that requires recirculation and early breakthrough, a smaller well spacing between injectors/producers (such as doublets) should be considered. Therefore, geological carbon storage is an ancillary objective of such operations, whereas primarily $\mathrm{CO}_{2}$ will be used as transmission fluid (Brown 2000; Pruess 2006; Xu et al. 2008; Buscheck et al. 2012a, b).

Alternatively, $\mathrm{CO}_{2}$ can be used, in farther well spacing, for geothermal reservoir systems such as hydrothermal reservoirs and hot sedimentary aquifers with naturally sufficiently porous and permeable formations overlain by caprock. The goal of injecting $\mathrm{CO}_{2}$ is then to provide the necessary pressure of fluid production and to displace native formation fluid (e.g. brine or hydrocarbons). In this so-called $\mathrm{CO}_{2}$-plume geothermal (CPG) approach (Randolph and Saar 2011a, b; Adams et al. 2014; Ganjdanesh et al. 2015) the working fluid is not necessarily $\mathrm{CO}_{2}$ only, and contrary to the first application, a key objective is to provide simultaneous $\mathrm{CO}_{2}$-injection-induced pressure relief by producing hot brine with consumptive beneficial uses (Buscheck et al. 2012b). The purpose also shifts to maximise brine production (i.e. energy and heat) and minimise $\mathrm{CO}_{2}$ production to increase $\mathrm{CO}_{2}$ storage capacity and efficiency. If the reservoir is overpressurised by $\mathrm{CO}_{2}$ injection, various methodologies that are designed to manage, avoid and minimise pressure build-up in geological- $\mathrm{CO}_{2}$-storageonly operations [as reviewed comprehensively in Birkholzer et al. (2015)] can be adapted for geothermal heat recovery. Consequently between the two approaches (EGS where $\mathrm{CO}_{2}$ is used as transmission fluid and CPG where $\mathrm{CO}_{2}$ is used for storage and brine production), a same metric, i.e. amount of produced $\mathrm{CO}_{2}$, is favourable in opposite extremes. This metric will be directly dependent on the well spacing, number and pattern administered in the operation.

Lack of production history from non-hydrocarbon aquifer systems implies large uncertainty which leads to complexities and added level of required caution in operation planning and decision making. Therefore, the boundary conditions have also significant impact on the performance of $\mathrm{CO}_{2}$ injection into saline aquifers. From hydrodynamic point of view, it is extremely important to properly prescribe hydrogeological boundary conditions and quantify the flow and pressure support (or lack of it) based on formation geological and seismic data. The boundary conditions will represent (a) the lateral extent of the storage formations may prove to be compartmentalised or open and (b) will determine the reservoir-scale effective conductivity of the overlying low-permeable caprock. Aquifer flux from lateral boundaries of extensively large aquifers is unhindered; however, disruptive or faults-induced compartmentalised formations may demonstrate restricted-flow or no-flow barrier-like boundary conditions (Holloway 2009). Examples of compartmentalised geothermal reservoirs are Torre Alfina field in Italy (Vignaroli et al. 2013) and Rotokawa geothermal field in New Zealand (McNamara et al. 2016). 
From geothermal point of view, boundaries contribute to conduction as the prevalent mechanism of heat transfer for enhanced geothermal systems, whereas for hydrothermal aquifers, in addition to conduction, convection flow also contributes to the mass/heat transport phenomena (Franco and Vaccaro 2014). Background heat flow conduction is usually in order of $65-80 \mathrm{~mW} / \mathrm{m}^{2}$ (DiPippo 2012). To represent conductive basal heat flow, often a hot plate boundary condition is assumed; however, this technique provides an infinite source of hot water with spurious quasi steady state. DiPippo (2012) argues that it is better to extend the model vertically for $6-8 \mathrm{~km}$ so that the heat flow is realistically physically included; however, this comes with prohibitive computational overhead. An alternative approach is to assume additional pore volume attached to the boundaries of geothermal reservoir. Consequently, representing the heat conduction from base is challenging and requires extra care in modelling.

For combined thermo-hydrologic boundary conditions, a survey of recent literature publications shows different treatments in numerical models:

- Vogt et al. (2010) assumed the basal heat flow uncertain in a geothermal reservoir, in The Hague, Netherlands, to vary in the range of $63 \pm 3 \mathrm{~mW} / \mathrm{m}^{2}$.

- Randolph and Saar (2011a) used no-flow no-heat-flux boundary conditions at top and sides, and analytical heat conduction and no fluid flow for base for a theoretical CPG and EGS.

- Tutolo et al. (2015) for a 200 bar, $100{ }^{\circ} \mathrm{C}$ calcite and dolomite carbonate reservoirs prescribed the upper and lower domain boundaries with no-flow boundary conditions and prescribed the sides with hydrostatically equilibrated aquifers to allow heat and fluid flow.

- Saeid et al. (2015) prescribed heat flux and flow rate at top for a prototypical model of deep low-enthalpy hydrothermal systems.

- Xu et al. (2015a) prescribed no heat and fluid flow on the lateral boundaries of a theoretical EGS system.

Above-mentioned research works demonstrate the importance, uncertainty and varying representability in thermo-hydrologic boundary conditions. Amongst the reviewed articles, no work has systematically examined the effect of boundary conditions on the $\mathrm{CO}_{2}$-geothermal system performance measures. To elucidate the effects of boundary conditions specifically for an integrated carbon sequestration-geothermal heat recovery from sedimentary aquifers with sufficient permeability and porosity (CPG), I define and conduct an extensive series of simulations. I also assess effects of varying well numbers by choosing three patterns of well spacing. Our objectives are to quantify the boundary conditions- and well spacing-induced change in key performance indicators of the operation, namely the changes in $\mathrm{CO}_{2}$ storage efficiency, net accumulated $\mathrm{CO}_{2}$ in the system, geothermal heat recovery and salt precipitation. In order to be able to isolate the effects of boundary condition and well spacing on the outputs, I impose restricting and unrealistic assumptions such as homogeneity and isotropicity of the geothermal model, simplicity of boundary water influx and outflux and confinement of the aquifer from top and base with respect to heat and fluid flows.

\subsection{Outline}

The paper is structured as following. In Sect. 2, the simulator chosen for studies and the synthetic model of hot sedimentary aquifer under study are described. In Sect. 3, the simulation runs and the performance metrics are defined. In Sect. 4, results will be presented, which is followed by Sect. 5 for conclusions and future research considerations. 


\section{Simulator and Model of Geothermal Reservoir}

I use Schlumberger ECLIPSE E300 simulator, capable of conducting compositional modelling of $\mathrm{CO}_{2}$-geothermal heat recovery operations for geothermal aquifers that contain $\mathrm{NaCl}$ and $\mathrm{CaCl}_{2}$. The simulator solves the coupled mass continuity and energy equations, using Darcy's law to describe multiphase flow. Mutual solubilities of $\mathrm{CO}_{2}$ and $\mathrm{H}_{2} \mathrm{O}$ are calculated by phase partitioning model (Spycher and Pruess 2005, 2010) to match the experimental data in the range of $12-250{ }^{\circ} \mathrm{C}$ and up to 600 bars. Alongside the following first three reactions for speciation of water and aqueous $\mathrm{CO}_{2}$, the following last two equilibrium reactions are used to determine $\mathrm{NaCl}$ and $\mathrm{CaCl}_{2}$ mol present in the aqueous phase and the solid phase:

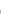$$
\mathrm{H}_{2} \mathrm{O} \rightleftharpoons \mathrm{H}^{+}+\mathrm{OH}^{-}
$$$$
\mathrm{CO}_{2}(\mathrm{aq})+\mathrm{H}_{2} \mathrm{O} \rightleftharpoons \mathrm{HCO}_{3}^{-}+\mathrm{H}^{+}
$$$$
\mathrm{HCO}_{3}^{-} \rightleftharpoons \mathrm{CO}_{3}^{2-}+\mathrm{H}^{+}
$$$$
\mathrm{CaCl}_{2} \text { (solid) } \rightleftharpoons \mathrm{Ca}^{2+}(\mathrm{aq})+2 \mathrm{Cl}^{-}(\mathrm{aq})
$$$$
\mathrm{NaCl}(\text { solid }) \rightleftharpoons \mathrm{Na}^{+}(\mathrm{aq})+\mathrm{Cl}^{-}(\mathrm{aq})
$$

In "Appendix A", a brief overview of the fluid properties in presence of salt and the main governing equations are provided. I use a simple horizontal, rectangular $(3 \mathrm{~km} \times 3 \mathrm{~km} \times 100 \mathrm{~m})$, homogenous, isotropic model of a hot sedimentary aquifer, as shown in Fig. 1. The constant values for the rock and fluid parameters are reported in Table 1. The top of the model is $2000 \mathrm{~m}$ deep. Pressure of $200 \mathrm{bar}$ and temperature of $80{ }^{\circ} \mathrm{C}$ at $2000 \mathrm{~m}$ are imposed for initialisation. As such, the theoretical geothermal reservoir in this work is classified as low-enthalpy or low-temperature systems and is tried to replicate the depth, initial pressure and temperature of fluvial Delft Sandstone Member with $3 \mathrm{k} / 100 \mathrm{~m}$ temperature gradient (Bonté et al. 2012; Salimi and Wolf 2012; Crooijmans et al. 2016). Also, for high-enthalpy reservoirs (i.e. $T>200{ }^{\circ} \mathrm{C}$ ), the flash calculations in ECLIPSE E300 fail. Therefore, the justification to choose a low-enthalpy reservoir is also based on the limitation of the simulator.

The pressure gradient in the system is ignored, and the model is initialised with uniform $80{ }^{\circ} \mathrm{C}$. An initial aqueous ion concentration analysis shows speciation of $91.0 \mathrm{~g} / \mathrm{L} \mathrm{Na}^{+}$, $22.6 \mathrm{~g} / \mathrm{L} \mathrm{Ca}^{2+}$ and $\mathrm{Cl}^{-} \mathrm{g} / \mathrm{L}$ concentration. For a water density of $936.2 \mathrm{~kg} / \mathrm{m}^{3}$ at reservoir condition, the analysis corresponds to overall molar composition of $0.92 \mathrm{H}_{2} \mathrm{O}, 0.07 \mathrm{NaCl}$ and $0.01 \mathrm{CaCl}_{2}$, or $\sim 24 \%$ salt mass fraction in brine, and equivalent salt molality of $4.83 \mathrm{~g} \mathrm{~mol} / \mathrm{kg}$ across the geothermal system. ${ }^{1}$

\footnotetext{
${ }^{1}$ The concentrations give $n_{\mathrm{H}_{2} \mathrm{O}}=m_{\mathrm{H}_{2} \mathrm{O}} / M W_{\mathrm{H}_{2} \mathrm{O}}=936.2 / 18=52.01 \mathrm{~g} \mathrm{~mol}, n_{\mathrm{Na}^{+}}=$ $m_{\mathrm{Na}^{+}} / M W_{\mathrm{Na}^{+}}=91 / 23=3.96 \mathrm{~g} \mathrm{~mol}, n_{\mathrm{Ca}^{2+}}=m_{\mathrm{Ca}^{2+}} / M W_{\mathrm{Ca}^{2+}}=22.6 / 40=0.565 \mathrm{~g} \mathrm{~mol}$, and $n_{\mathrm{Cl}^{-}}=$ $m_{\mathrm{Cl}^{-}} / M W_{\mathrm{Cl}^{-}}=141 / 35=4.03 \mathrm{~g}$ mol. Since $\mathrm{CaCl}_{2} \rightleftharpoons \mathrm{Ca}^{2+}+2 \mathrm{Cl}^{-}$and $\mathrm{NaCl} \rightleftharpoons \mathrm{Na}^{+}+\mathrm{Cl}^{-}$, therefore after equilibration $n_{\mathrm{NaCl}(\text { aq) }}=n_{\mathrm{Na}^{+}}$and $n_{\mathrm{CaCl}_{2} \text { (aq) }}=n_{\mathrm{Ca}^{2+}}$, so $n_{\text {total }}=n_{\mathrm{H}_{2} \mathrm{O}}+n_{\mathrm{NaCl} \text { (aq) }}+n_{\mathrm{CaCl}_{2} \text { (aq) }}=$

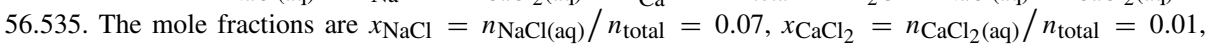
and $x_{\mathrm{H}_{2} \mathrm{O}}=n_{\mathrm{H}_{2} \mathrm{O}} / n_{\text {total }}=0.92$. The molality is $\left(n_{\mathrm{NaCl}(\mathrm{aq})}+n_{\mathrm{CaCl}_{2}(\mathrm{aq})}\right) /\left(m_{\mathrm{H}_{2} \mathrm{O}}\right.$ of $1 \mathrm{~L}$ in kg) $=4.83$ $\mathrm{g} \mathrm{mol} / \mathrm{kg}$, and salinity is $10^{6} \times\left(m_{\mathrm{Na}^{+}}+m_{\mathrm{Ca}^{2+}}\right) / m_{\mathrm{H}_{2} \mathrm{O}}=121,000 \mathrm{ppm}$.
} 


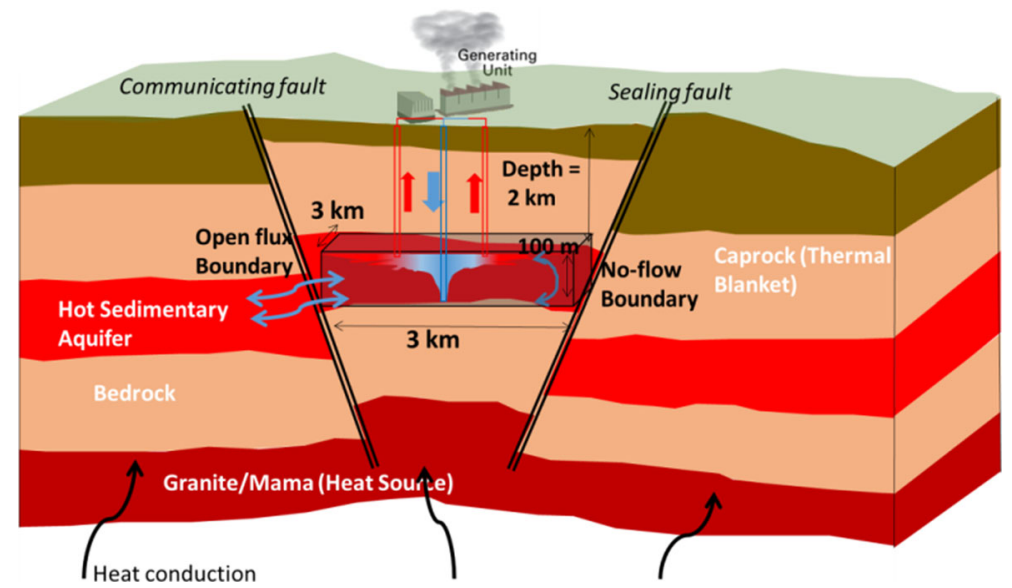

Fig. 1 Schematic of hot sedimentary system with open and close boundary conditions

Table 1 Several rock and fluid properties of the geothermal system

\begin{tabular}{ll}
\hline Property & Denotation and value \\
\hline Rock density & $\rho_{\mathrm{r}}=2650 \mathrm{~kg} / \mathrm{m}^{3}$ \\
Absolute permeability & $k=20 \mathrm{mD}$ \\
Rock compressibility & $c_{\mathrm{r}}=7 \times 10^{-5} \mathrm{bar}^{-1}$ at $200 \mathrm{bar}$ \\
Porosity & $\phi=0.15$ \\
Rock heat capacity & $h_{\mathrm{r}}=0.75 \mathrm{~kJ} / \mathrm{kg} / \mathrm{K}$ \\
Vertical to horizontal permeability & $k_{\mathrm{V}} / k_{\mathrm{h}}=1$ \\
Rock and solid phase thermal conductivity & $\kappa_{\mathrm{r}}=2.1 \mathrm{~W} / \mathrm{m} / \mathrm{K}$ \\
Net-to-gross ratio & $\mathrm{ntg}=1$ \\
Brine thermal conductivity & $\kappa_{\mathrm{W}}=0.58 \mathrm{~W} / \mathrm{m} / \mathrm{K}$ \\
CO ${ }_{2}$ thermal conductivity & $\kappa_{\mathrm{g}}=0.0146 \mathrm{~W} / \mathrm{m} / \mathrm{K}$ \\
Relative permeability & $k_{\mathrm{r} \alpha}=\left(S_{\alpha}\right)^{2}$ \\
Residual water and gas saturation & 0 \\
Capillary pressure & 0 \\
\hline
\end{tabular}

In this study, the choices of boundary conditions are limited to

- Hydrologically and thermally fully open from all lateral sides (free heat and fluid flow), fully close and sealed from top and base (no convective a conductive heat and no fluid flow)

- Hydrologically and thermally fully close from all lateral and horizontal sides.

For open boundary condition I assume the geothermal system is in unconfined mass and heat communication with the surrounding side aquifers through additional pore volume. To replicate this situation, I use pore volume multipliers on the boundary gridblocks to enlarge their pore volume by a factor of 1000 . This number is arbitrarily chosen to implicate an infinite acting aquifer; nevertheless, smaller numbers could have been chosen with the same effect. For the case of close boundary condition, I assume the reservoir is sealed from the four sides and there is no heat and mass communication between the geothermal system and 

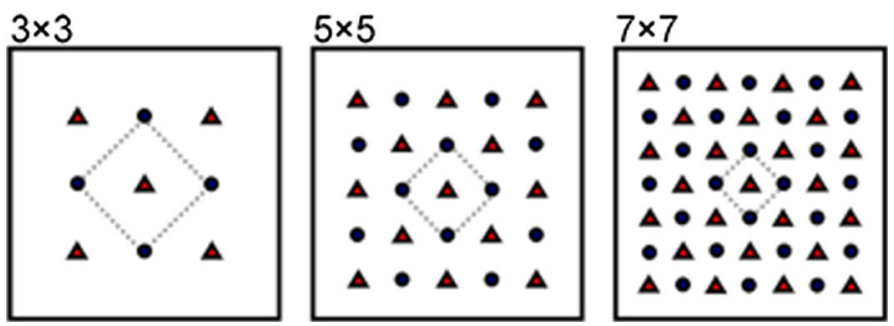

Fig. 2 From (Heath et al. 2014): map view of well layouts in the geothermal resource model under study. From left to right, the well layouts are $3 \times 3,5 \times 5$ and $7 \times 7$. Triangles are $\mathrm{CO}_{2}$ injectors, whereas circles are brine extractors. The dotted grey lines highlight inverted five-spot well placement

surrounding aquifers. For the illustration purposes, the top and bottom of the geothermal system are assumed fully bounded by low-permeable strata, and neither overburden nor underburden conductive heat transfer occurs across these faces.

\section{Simulation Runs and Performance Metrics}

\subsection{Simulation Runs}

Substantial attention has been paid to well spacing and placement optimisation for maximising $\mathrm{CO}_{2}$ storage and capacity (Cameron and Durlofsky 2012; Vogt 2013; Cihan et al. 2015; Chen et al. 2015; Babaei et al. 2015). In addition to well spacing, there are numerous operation parameters to be treated as state variables of optimisation, such as number of wells, angle of preformation and inclination, and injection scheduling. To facilitate conclusiveness on effects of well spacing, number and pattern, I simplify the problem by assuming three regular layouts of the well placement in the reservoir as shown in Fig. 2. The same layouts have been used to study the $\mathrm{CO}_{2}$ storage efficiency in carbon sequestration in saline aquifers by Heath et al. (2014). Here, I adapt these layouts to calculate heat recovery as well as $\mathrm{CO}_{2}$ storage efficiency. These layouts are referred to as $3 \times 3,5 \times 5$ and $7 \times 7$ well patterns that include 5, 13 and 25 injection wells, and 4, 12 and 24 production wells, respectively. The dotted grey lines in these patterns represent inverted five-spot well placement. For all layouts I use $60 \times 60 \times 10=36,000$ gridblocks for simulation. Therefore, I include the effects of gravity override in the simulations.

Pure $\mathrm{CO}_{2}$ is injected at $20^{\circ} \mathrm{C}$. The injection from the injectors is conducted by dividing a specified total injection rate of $\mathrm{CO}_{2}, Q_{\text {inj }}$, between the available injection wells. The perforations go through all 10 reservoir layers. The injection mode is constant injection rate with very large allowable bottomhole pressure of 500 bar. I use 3 total volumetric injection rates of $1.5 \times 10^{6}, 3 \times 10^{6}$ and $4.5 \times 10^{6} \mathrm{sm}^{3} /$ day, where $\mathrm{sm}^{3}$ stands for standard-condition cubic metre. Considering a standard-condition $\mathrm{CO}_{2}$ density of $1.98 \mathrm{~kg} / \mathrm{sm}^{3}$, the mass injection rates are $34.375 \mathrm{~kg} / \mathrm{s}(\sim 1.08$ million tonne per annum $), 68.750 \mathrm{~kg} / \mathrm{s}(\sim 2.17$ million tonne per annum) and $103.125 \mathrm{~kg} / \mathrm{s}(\sim 3.25$ million tonne per annum). The injection period is 20 years. The production of fluid from extraction wells is conducted at constant bottomhole pressures of $P_{\mathrm{bh}}$ of 200, 180 and $160 \mathrm{bar}$. The first pressure will provide a case of constrained extraction where the reservoir pressure is maintained close to its initial level. In the second and third runs, the constraint is relaxed so that fluid is produced more easily from the reservoir. It is 
Table 2 Fifty-four simulation runs defined for the multiparametric analysis of this study

\begin{tabular}{llll}
\hline Boundary condition type & $\begin{array}{l}\text { Production bottomhole } \\
\text { pressure }\left(P_{\text {bh }}\right)(\text { bar })\end{array}$ & Well pattern & $Q_{\text {inj }}\left(\mathrm{sm}^{3} /\right.$ day $)$ \\
\hline Open & 200 & $3 \times 3$ & $1.5 \times 10^{6}$ \\
Close & 180 & $5 \times 5$ & $3.0 \times 10^{6}$ \\
& 160 & $7 \times 7$ & $4.5 \times 10^{6}$ \\
\hline
\end{tabular}

noteworthy that, the results of this work will be different if other well control modes were selected and the conclusions of this work are only valid for the prescribed control modes.

In total, I perform 54 simulation runs as summarised in Table 2. The simulation models contain 36,000 gridblocks of size $50 \mathrm{~m} \times 50 \mathrm{~m} \times 10 \mathrm{~m}$. The simulations are conducted using Schlumberger's ECLIPSE E300 compositional simulator (Schlumberger 2014b).

\subsection{Performance Metrics}

\subsection{1 $\mathrm{CO}_{2}$ Injection Metrics}

From the numerical simulation results, one can obtain the mass of $\mathrm{CO}_{2}$ accumulated in the global domain (mass-in-place), expressed in million tonnes of $\mathrm{CO}_{2}(\mathrm{Mt})$, as:

$$
\mathrm{MIP}_{\mathrm{CO}_{2}}^{t}=M_{\mathrm{inj}}^{t}-M_{\mathrm{prd}}^{t}+\mathrm{MIIP}
$$

where $M_{\mathrm{inj}}^{t}, M_{\mathrm{prd}}^{t}$ and MIIP (Mt) are, respectively, the cumulative mass of injected $\mathrm{CO}_{2}$, the cumulative mass of produced $\mathrm{CO}_{2}$, and the mass initially in place of $\mathrm{CO}_{2}$ in the global domain of the geothermal system, all at time $t$. In this formulation, $\mathrm{MIP}_{\mathrm{CO}_{2}}^{t}$ refers to the accumulated mass of $\mathrm{CO}_{2}$ in the subsurface system in any state, i.e. either free $\mathrm{CO}_{2}$ in its own phase ( $\mathrm{MIP}_{\text {gas }}^{t}$ ) or dissolved in aqueous phase. $\left(\mathrm{MIP}_{\text {dis }}^{t}\right)$. For an optimal storage of $\mathrm{CO}_{2}$, the dissolved amount of $\mathrm{CO}_{2}$ must be enhanced. The net mass of $\mathrm{CO}_{2}$ that is left in the geothermal system at time $t$ is:

$$
M_{\text {net }}^{t}=M_{\mathrm{inj}}^{t}-M_{\mathrm{prd}}^{t}
$$

I define a dimensionless $\mathrm{CO}_{2}$ injection efficiency factor as:

$$
e_{\mathrm{inj}}^{t}=\frac{M_{\mathrm{inj}}^{t}-M_{\mathrm{prd}}^{t}}{M_{\mathrm{inj}}^{t}}
$$

that points to the fraction of injected $\mathrm{CO}_{2}$ that is in place at time $t$.

In the absence of numerical simulation, the researchers have defined a "volumetric" storage efficiency factor, $e_{\mathrm{CO}_{2}}$, as the fraction of the total pore volume occupied with the injected free-phase $\mathrm{CO}_{2}$. This parameter is a function of various geologic factors including net-togross ratio, effective-to-total porosity, and the areal, vertical, and macroscopic displacement efficiency [a full review is presented by Bachu (2015)]. By generalising $e_{\mathrm{CO}_{2}}$ for similar reservoir or storage units, engineers can estimate the total mass of $\mathrm{CO}_{2}$ that can be stored in the storage site by $\mathrm{MIP}_{\mathrm{CO}_{2}}=V_{\mathrm{p}} \times e_{\mathrm{CO}_{2}} \times \rho_{\mathrm{CO}_{2}}$. In numerical simulations, $e_{\mathrm{CO}_{2}}$ can be

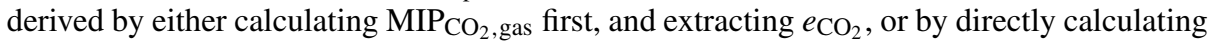


the volume of free-gas $\mathrm{CO}_{2}$ from the numerical gridblocks of the domain with the pore volume of $V_{\mathrm{p}}$ :

$$
e_{V, \mathrm{CO}_{2}}^{t}=\frac{\sum_{i=1}^{N_{\mathrm{b}}} S_{\mathrm{g}, i}^{t} V_{i} \phi_{i}^{t}}{V_{\mathrm{p}}}
$$

where $N_{\mathrm{b}}$ is the number of gridblocks within the domain, and $S_{\mathrm{g}, i}, V_{i}$, and $\phi_{i}$ are $i$ th gridblock gas saturation, volume and porosity, respectively, at the end of simulation.

\subsubsection{Heat Recovery Metrics}

The global net heat recovered by the operation is

$$
E_{\text {net }}^{t}=E_{\mathrm{prd}}^{t}-E_{\mathrm{inj}}^{t}
$$

where $E_{\mathrm{inj}}^{t}$ and $E_{\mathrm{prd}}^{t}$ are, respectively, the energy injected by the injectors and energy produced by the producers, at time $t$. These are calculated based on the temperature of injection and production streams in ECLISPE E300.

The available heat in the rock and fluid at initial time is denoted by EIIP (energy initially in place) and is calculated from the porosity-averaged heat capacity of rock and brine:

$$
\mathrm{EIIP}=\sum_{i=1}^{N_{\mathrm{b}}} V_{\mathrm{b}, i} e_{i}=\sum_{i=1}^{N_{\mathrm{b}}}\left[\phi_{i} V_{i}\left(\hat{S}_{\mathrm{g}, i} b_{\mathrm{g}, i} e_{\mathrm{g}, i}+\hat{S}_{\mathrm{w}, i} b_{\mathrm{w}, i} e_{\mathrm{w}, i}+\hat{S}_{\mathrm{s}, i} b_{\mathrm{s}, i} e_{\mathrm{s}, i}\right)+\left(1-\phi_{i}\right) V_{i} e_{\mathrm{r}, i}\right]
$$

where $V_{\mathrm{b}, i}$ is the $i$ th gridblock bulk volume, and $e_{i}$ is the $i$ th gridblock effective total energy; $e_{\mathrm{g}, i}, e_{\mathrm{w}, i}$, and $e_{s, i}(\mathrm{~kJ} / \mathrm{kg} \mathrm{mol})$ are, respectively, $i$ th gridblock internal-energy molar densities of gas, water and solid phases; $b_{\mathrm{g}, i}, b_{\mathrm{w}, i}$ and $b_{\mathrm{s}, i}\left(\mathrm{~kg} \mathrm{~mol} / \mathrm{m}^{3}\right)$ are, respectively, molar densities of gas, water and solid phases; and $e_{\mathrm{s}, i}\left(\mathrm{~kJ} / \mathrm{m}^{3}\right)$ is the energy per unit volume of rock calculated from rock heat capacity and rock density. Phase internal-energy densities and phase enthalpies are assumed to be equal $(U=H)$. A geothermal heat recovery factor is defined as:

$$
r_{\mathrm{g}}^{t}=\frac{E_{\text {net }}^{t}}{\mathrm{EIIP}}
$$

In summary, in a multiparametric analysis of performance of the operation, the effect of well number, open versus close systems and injection rate on $M_{\mathrm{net}}^{t}$ and $e_{\mathrm{inj}}^{t}, e_{V, \mathrm{CO}_{2}}^{t}$ and $r_{\mathrm{g}}^{t}$ are compared. Additionally, $\max \left(\hat{S}_{\mathrm{s}}^{t}\right)$ (maximum solid saturation at time $t$ ) between the simulation runs are compared.

\section{Results}

\subsection{System Behaviour}

I start presenting results for operation with production $P_{\mathrm{bh}}$ of 200 bar. Figure 3 shows the gas saturation distribution for the lowest injection rate $\left(1.5 \times 10^{6} \mathrm{sm}^{3} /\right.$ day $)$ for different well patterns after 5 years of injection. The reason year 5 is chosen, is that around this year the plumes start to reach the production wells, and thereafter, the $\mathrm{CO}_{2}$ is back-produced (as will be shown in Fig. 5). Similar to the work of Heath et al. (2014), the discrepancy between the $\mathrm{CO}_{2}$ saturation distributions of the close and open systems is only dramatic for the $3 \times 3$ well 

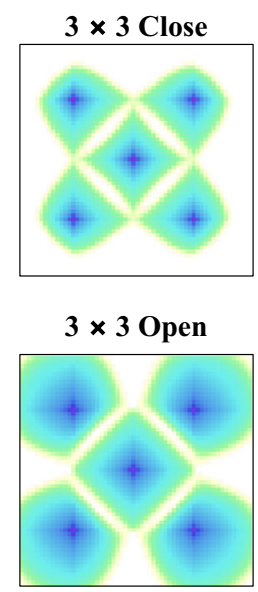
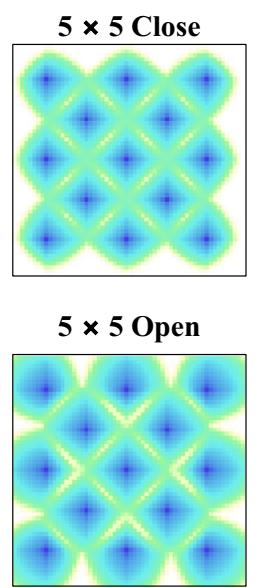

$7 \times 7$ Close

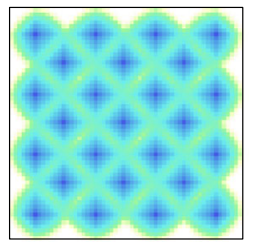

Gas saturation

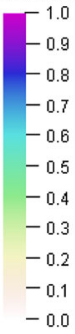

Fig. 3 The gas saturation distribution in the domain after 5 years of injection for volumetric injection rate of $1.5 \times 10^{6} \mathrm{sm}^{3} /$ day

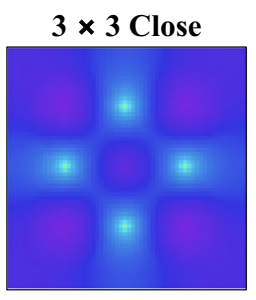

$3 \times 3$ Open

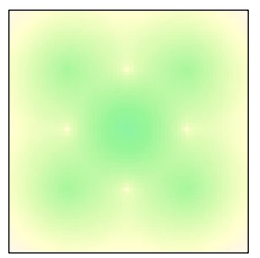

$5 \times 5$ Close

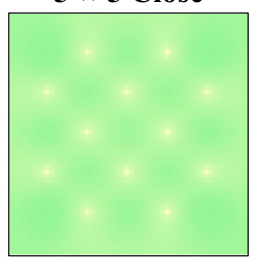

$5 \times 5$ Open

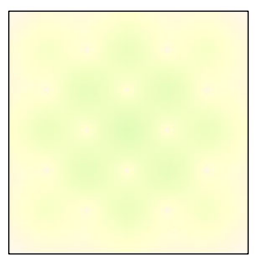

$7 \times 7$ Open

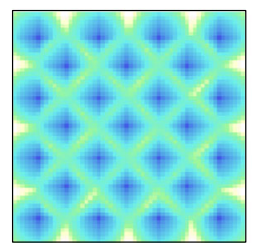




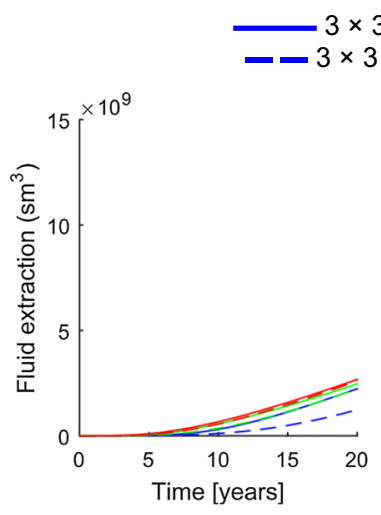

(a)

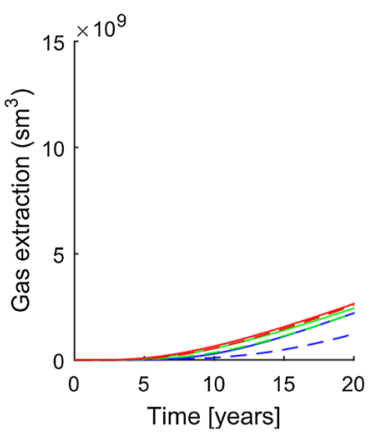

(d)

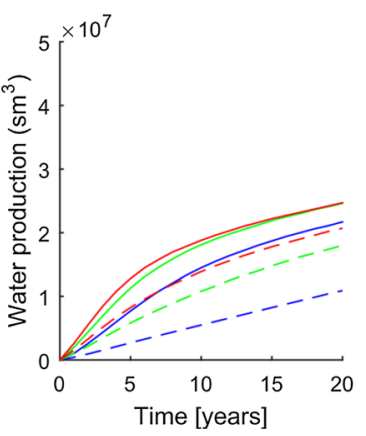

(g)

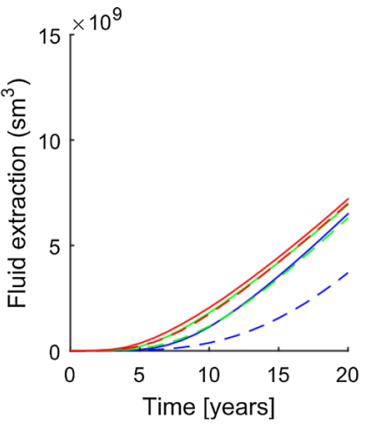

(b)

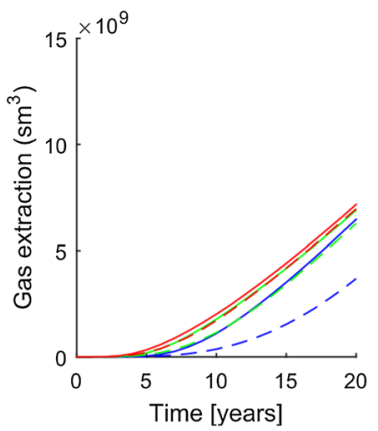

(e)

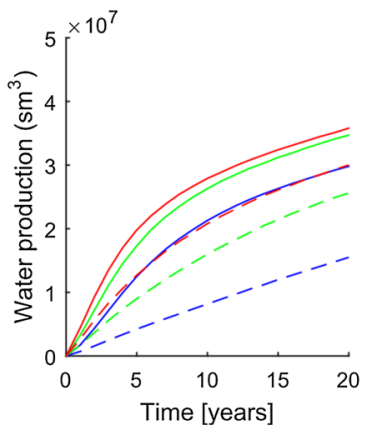

(h)
$7 \times 7$ close
$7 \times 7$ open

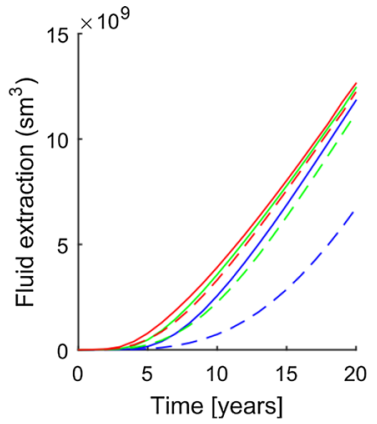

(c)

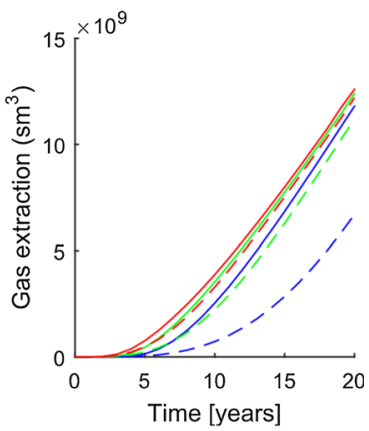

(f)

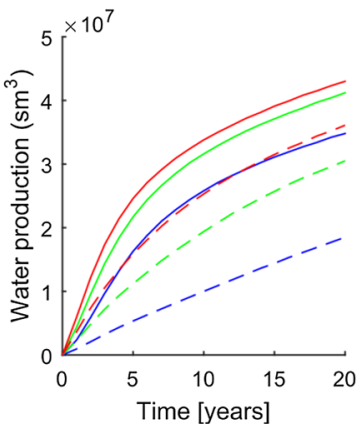

(i)

Fig. 5 The fluid extraction/gas production/water production profiles for $\mathbf{a}, \mathbf{d}, \mathbf{g} Q=1.5 \times 10^{6} \mathrm{sm}^{3} / \mathrm{day}, \mathbf{b}, \mathbf{e}, \mathbf{h}$ $Q=3 \times 10^{6} \mathrm{sm}^{3} /$ day and $\mathbf{c}, \mathbf{f}, \mathbf{i} Q=4.5 \times 10^{6} \mathrm{sm}^{3} /$ day

wells, higher injection rates may jeopardise the integrity of the caprock. The influence of system boundaries on pressure build-up becomes less pronounced by increasing number of wells in the $5 \times 5$ and $7 \times 7$ well patterns. In the longer 20 -year window, however, for all the simulations, the pressure build-up for open and close systems converges. This shows that a circulation of $\mathrm{CO}_{2}$ is established. 


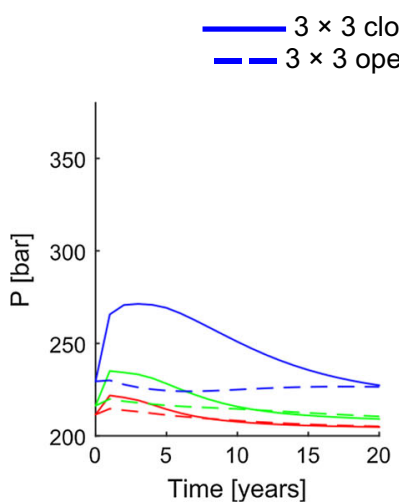

(a)

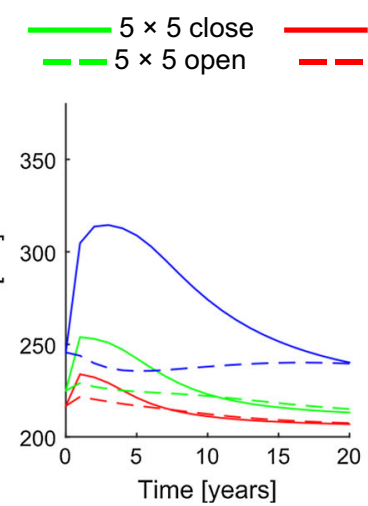

(b)
$7 \times 7$ close
$7 \times 7$ open

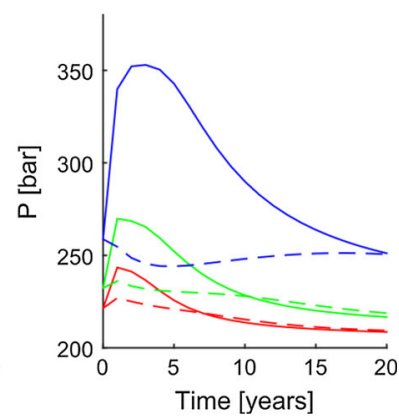

(c)

Fig. 6 The pressure profiles for a $Q=1.5 \times 10^{6} \mathrm{sm}^{3} /$ day, $\mathbf{b} Q=3 \times 10^{6} \mathrm{sm}^{3} /$ day and $\mathbf{c} Q=4.5 \times 10^{6} \mathrm{sm}^{3} /$ day

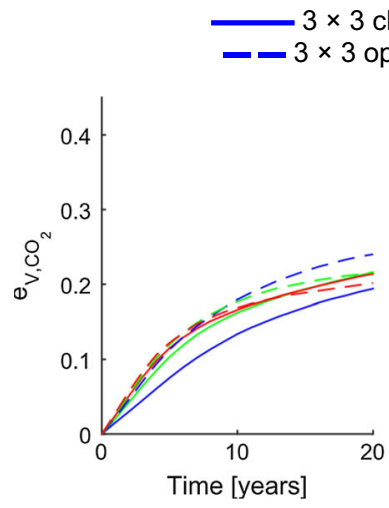

(a)

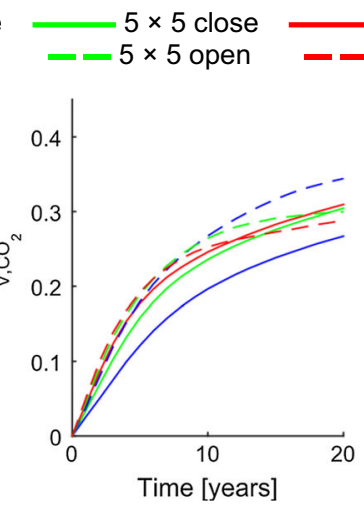

(b)
$7 \times 7$ close

$7 \times 7$ open

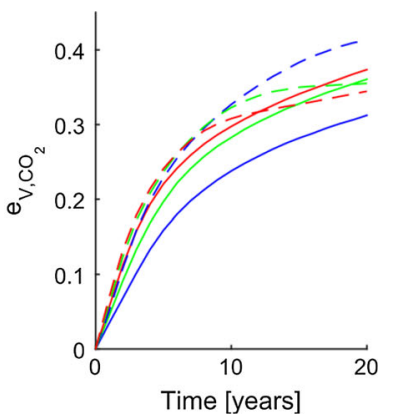

(c)

Fig. 7 The $\mathrm{CO}_{2}$ storage efficiency for a $Q=1.5 \times 10^{6} \mathrm{sm}^{3} /$ day, b $Q=3 \times 10^{6} \mathrm{sm}^{3} /$ day and $\mathbf{c} Q=4.5 \times 10^{6}$ $\mathrm{sm}^{3} /$ day

\section{2 $\mathrm{CO}_{2}$ Storage Metrics}

The conclusion made earlier (reduction in the impact of system boundaries on performance measures) is corroborated by calculating $\mathrm{CO}_{2}$ storage efficiency $\left(e_{V, \mathrm{CO}_{2}}^{t}\right)$ throughout the simulation for different runs as shown collectively in Fig. 7. While, the curves are different in magnitude for the $3 \times 3$ well pattern between close and open systems, the discrepancy between the curves has decreased for the $5 \times 5$ well pattern, and the curves have almost converged with a negligible difference for the $7 \times 7$ well pattern. By increase in the injection rate, $e_{V, \mathrm{CO}_{2}}^{t}$ has increased regardless of the system boundaries. The values of $e_{V, \mathrm{CO}_{2}}^{t}$ here are larger than the typical values obtained for $\mathrm{CO}_{2}$ storage in saline aquifers because (1) brine is extracted in $\mathrm{CO}_{2}$-geothermal heat recovery that enhances the storage efficiency significantly and (2) circulation and back-production of $\mathrm{CO}_{2}$ is allowed.

Figure 8 shows $M_{\text {net }}^{t}$ for various simulation runs. There is a slight advantage in operating with the $3 \times 3$ well pattern in close system over $5 \times 5$ and $7 \times 7$ well patterns in terms of allowing more $\mathrm{CO}_{2}$ to be stored in the geothermal system by the end of simulation. In 


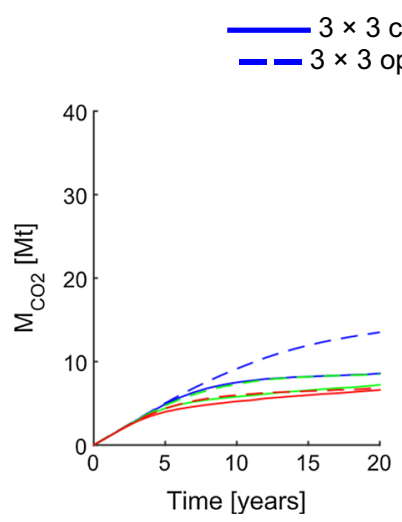

(a)

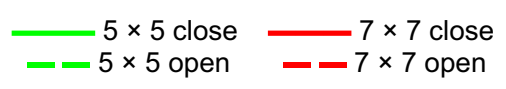

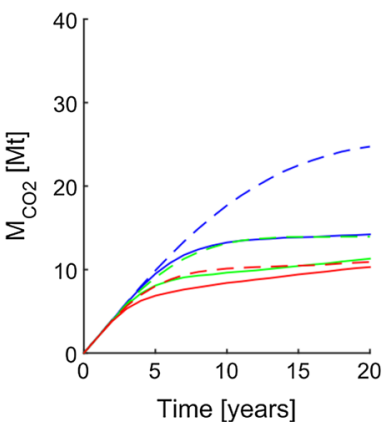

(b)

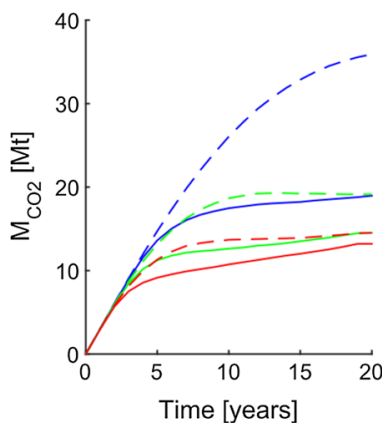

(c)

Fig. 8 The accumulated mass of $\mathrm{CO}_{2}$ for a $Q=1.5 \times 10^{6} \mathrm{sm}^{3} /$ day, $\mathbf{b} Q=3 \times 10^{6} \mathrm{sm}^{3} /$ day and $\mathbf{c} Q=4.5 \times 10^{6}$ $\mathrm{sm}^{3} /$ day

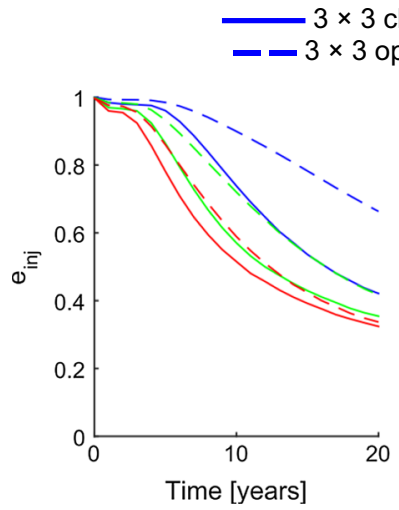

(a)

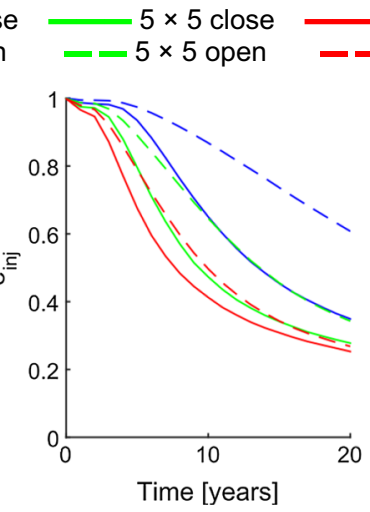

(b)
$7 \times 7$ close
$7 \times 7$ open

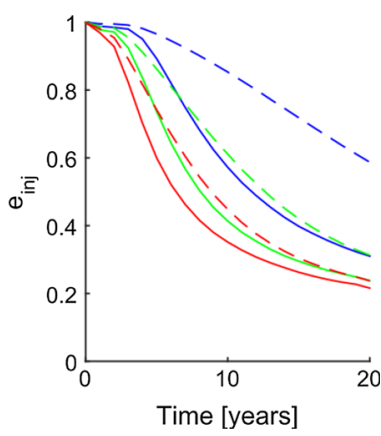

(c)

Fig. 9 The $\mathrm{CO}_{2}$ injection efficiency factor for a $Q=1.5 \times 10^{6} \mathrm{sm}^{3} /$ day, b $Q=3 \times 10^{6} \mathrm{sm}^{3} /$ day and c $Q$ $=4.5 \times 10^{6} \mathrm{sm}^{3} /$ day

contrast, for the open boundary condition, the $3 \times 3$ well pattern does not recover $\mathrm{CO}_{2}$ from the production wells as efficiently as in the $5 \times 5$ and $7 \times 7$ well patterns. Considering that the storage efficiency is the same between the well patterns for open boundary conditions, one can deduct that the injected $\mathrm{CO}_{2}$ is being lost only to the surrounding side aquifers for the $3 \times 3$ well pattern in open system. For the $3 \times 3$ well pattern in close system, since there is no loss of $\mathrm{CO}_{2}$ to the side aquifers, and the amounts of $\mathrm{CO}_{2}$ staying in the geothermal system is almost the same for all the well patterns, the pressure build-up can only be attributed to lower fluid extraction levels. Hence, a higher pressure of the system applied on the $\mathrm{CO}_{2}$ will result in lower volumes of the plume, thereby reducing the storage efficiency, $e_{V, \mathrm{CO}_{2}}^{t}$ compared to $5 \times 5$ and $7 \times 7$ well patterns. Finally as of $e_{V, \mathrm{CO}_{2}}^{t}$, the increase in operating injection rate has positive feedback on the net mass of stored $\mathrm{CO}_{2}$ in the system.

Figure 9 shows the profile of injection efficiency factor $\left(e_{\mathrm{inj}}^{t}\right)$. The curves demonstrate a slight decrease in $e_{\text {inj }}^{t}$ by increase in injection rate. 


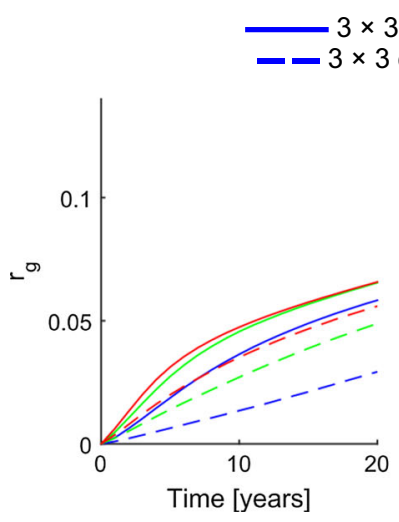

(a)

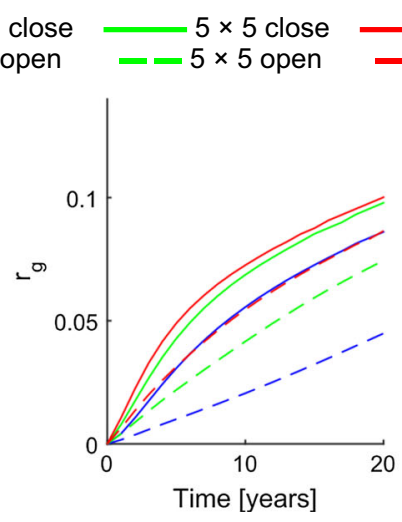

(b)
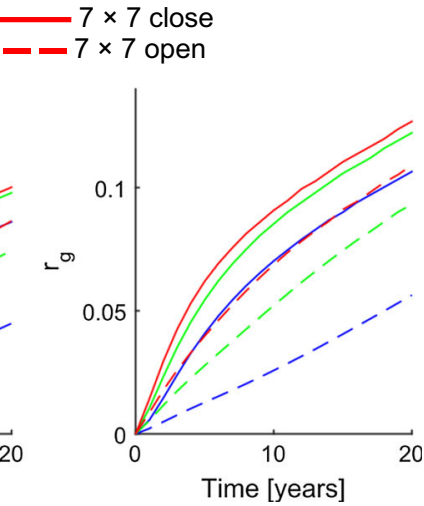

(c)

Fig. 10 The geothermal heat recovery factor for a $Q=1.5 \times 10^{6} \mathrm{sm}^{3} /$ day, b $Q=3 \times 10^{6} \mathrm{sm}^{3} /$ day and $\mathbf{c} Q$ $=4.5 \times 10^{6} \mathrm{sm}^{3} /$ day

\subsection{Geothermal Heat Recovery}

Figure 10 shows the profiles of geothermal heat recovery factor $\left(r_{\mathrm{g}}^{t}\right)$ for various simulation runs. Following interpretations can be deducted from this figure:

(1) Close system has resulted in higher heat recovery factors than the open system for all the well patterns considered in this study. This can be attributed to the negative role of the additional pore volume that allows migration of brine and $\mathrm{CO}_{2}$ from the main domain of the geothermal system. $\mathrm{CO}_{2}$ in its way pushes the hot aquifer brine away from the extraction wells, leading to poorer heat recovery. This is corroborated by considering the additional $M_{\text {net }}^{t}$ that the open boundary condition accommodates compared to close boundary condition.

(2) Regardless of the boundaries being open or close, increasing the number of wells result in higher heat recovery factors by allowing more extracted volumes of fluids as shown in Fig. 5. The negative impact of boundary condition on heat recovery factor can be alleviated by increasing the number of wells, so that the difference between open and close systems of higher than 0.02 for the $3 \times 3$ well pattern will decrease to less than 0.01 for $7 \times 7$ well pattern.

(3) The increase in operating injection rate has a positive feedback on heat recovery, and the discrepancy of the profiles between open and close systems will be higher for higher injection rates.

\subsection{Salt Precipitation}

Figure 11 shows the maximum solid saturation accumulated in the system during the simulation. Previously, solid precipitation in the context of $\mathrm{CO}_{2}$ injection-geothermal heat recovery operations has been modelled and effects of salt precipitation have been investigated (Borgia et al. 2012; Xu et al. 2008; Tutolo et al. 2015; Xu et al. 2006). Following are the interpretations from Fig. 11:

(1) There is a sharp decrease in $\max \left(\hat{S}_{\mathrm{s}}\right)$ by increasing the well numbers and a nonlinear increase by increasing the injection rate. This can be attributed to the distribution of injection between more injection wells in the $7 \times 7$ well pattern than in the $3 \times 3$ well 


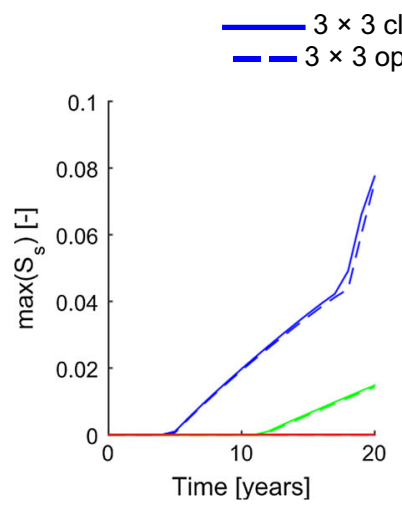

(a)

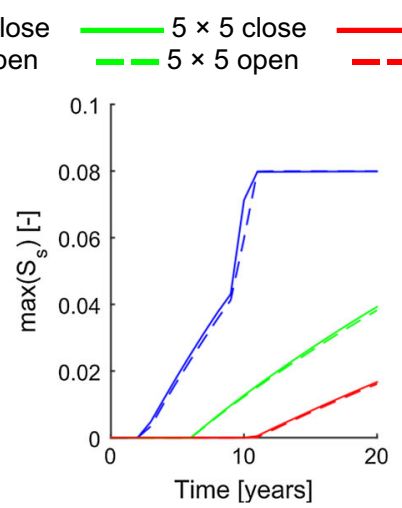

(b)
$7 \times 7$ close

$7 \times 7$ open

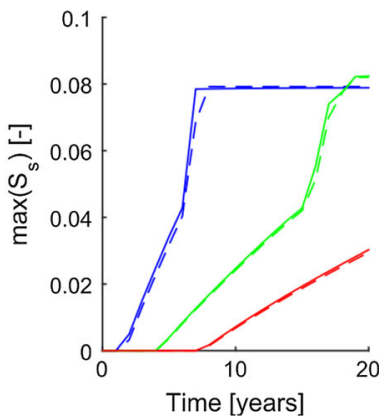

(c)

Fig. 11 The average solid saturation in the system for a $Q=1.5 \times 10^{6} \mathrm{sm}^{3} /$ day, $\mathbf{b} Q=3 \times 10^{6} \mathrm{sm}^{3} /$ day and c $Q=4.5 \times 10^{6} \mathrm{sm}^{3} /$ day

pattern. Using Eq. (A7) 30\% permeability reduction at injection sites for the $3 \times 3$ well pattern is estimated. For the $5 \times 5$ well pattern, only for the highest injection rate $\sim 30 \%$ permeability reduction occurs, and this reduction never occurs for $7 \times 7$ well pattern.

(2) The open or close boundaries have played no role in the magnitude and trend of the profiles. Since the initial conditions imposed such as pressure, temperature and salt mass fraction are comparable with $\mathrm{CO}_{2}$ storage analysis conducted by Guyant et al. (2015), the results are also comparable with their findings. The initial salt mass fraction leads to uniform precipitation of salt (not localised away from injection wells as for high- $k$ case). However, since the model here is based on a single-effective porosity, the results are not comparable with solid saturation distribution in a deep EGS as shown in Borgia et al. (2012, Fig. 7b) where the salt saturation is non-uniform and localised.

(3) $\max \left(\hat{S}_{\mathrm{S}}\right)$ has a non-reducing upper limit of $\sim 0.08$ for the $3 \times 3$ well pattern. Upper limit of max $\left(\hat{S}_{\mathrm{S}}\right)$ is higher for the $5 \times 5$ well pattern, is achieved only for the highest injection near the end of simulation. Upper limit of $\max \left(\hat{S}_{\mathrm{s}}\right)$ is not achieved for the $7 \times 7$ well pattern. Continuing the simulation may result in higher values for $\max \left(\hat{S}_{\mathrm{S}}\right)$ for the $5 \times 5$ and $7 \times 7$ well patterns. Salt deposition is accelerated by increasing the injection rate; however, its magnitude is injection rate independent. This result is comparable with conclusions derived by Pruess and Müller (2009) and Zeidouni et al. (2009). Injection of fresh brine at injection wells can re-dissolve the salt and retrieve the injectivity of the injection wells.

It should be noted that, prediction $\max \left(\hat{S}_{\mathrm{S}}\right)$ is extremely sensitive to the grid resolution ("Appendix C") as it is a function of the gridblock volume. Using higher resolution grid, the trend and magnitude of $\max \left(\hat{S}_{\mathrm{s}}\right)$ may vary significantly. This will have implications in terms of how porosity and permeability are affected by salt deposition near wellbore. As such, a careful investigation on how salt deposition is predicted by the simulation grid resolution is required. This will remain a matter of future investigations.

\subsection{Impact of Bottomhole Pressure}

Figure 12 condenses the output metrics discussed above calculated from simulations with $P_{\mathrm{bh}}$ of 200, 180 and 160 bar. For brevity purposes, only the results for the $3 \times 3$ well pattern and $Q=4.5 \times 10^{6} \mathrm{sm}^{3} /$ day are shown. Following are the interpretations extracted from Fig. 12 : 


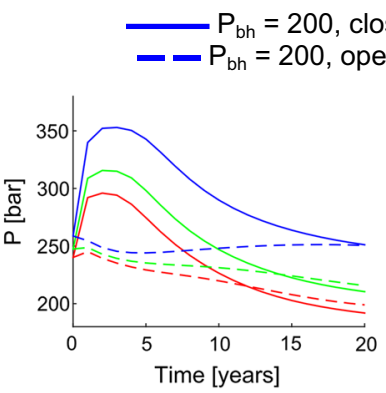

(a)

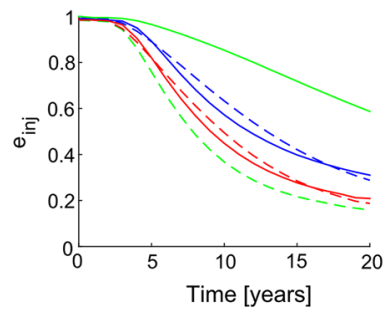

(d)

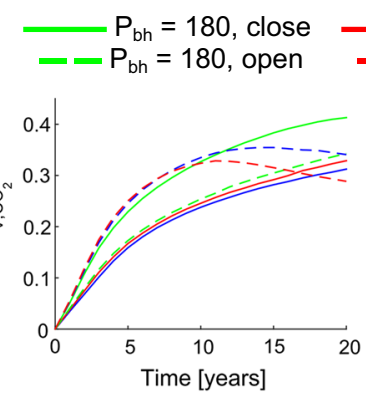

(b)

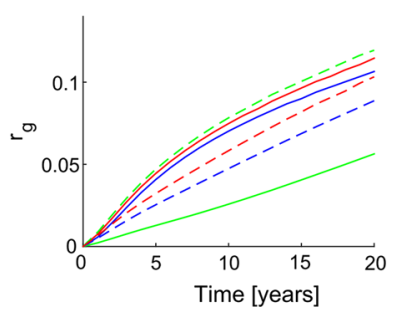

(e)

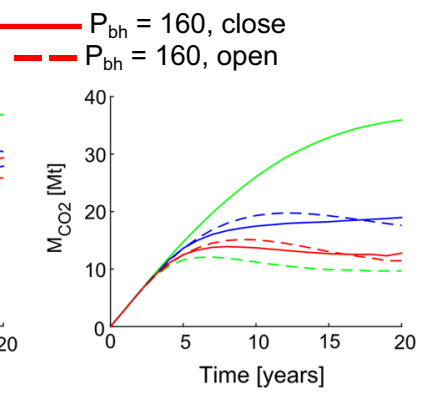

(c)

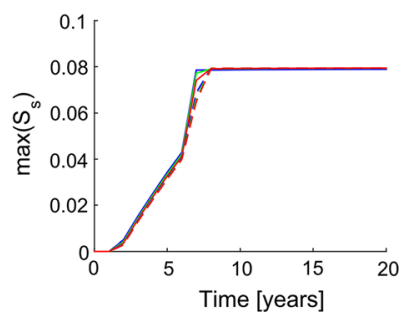

(f)

Fig. 12 The comparison of different output metrics for varying production $\mathrm{P}_{b h}$ simulations. a Injection $\mathrm{P}_{b h}$ profiles of the middle injection well, $\mathbf{b}$ storage efficiency factor, $\mathbf{c}$ the net amount of $\mathrm{CO}_{2}$ in place, $\mathbf{d}$ the injection efficiency factor, e geothermal heat recovery factor, and $\mathbf{f}$ the average solid saturation

(1) Fig. 12a, the reservoirs will be under hydrostatic pressure because of over-production of fluid by the end of simulations for $P_{\mathrm{bh}}=180$ bar and $P_{\mathrm{bh}}=160 \mathrm{bar}$. The support of open boundaries clearly helps to reduce the pressure drawdown.

(2) Fig. $12 \mathrm{~b}, \mathrm{c}$ shows that having open boundaries may not always help to maximise the injectivity, as in the case for $P_{\mathrm{bh}}=180$ bar and $P_{\mathrm{bh}}=160$ bar, the injected $\mathrm{CO}_{2}$ is first pushed to the outside of the domain in the open boundaries, and later (year 10) it starts to migrate back to the main domain to be produced by the production wells. The $\mathrm{CO}_{2}$ back-production for $P_{\mathrm{bh}}=160$ bar is so high that the actual amount of $\mathrm{CO}_{2}$ staying in the domain for close boundaries by the end of simulation is higher than its counterpart simulation with open boundaries, and final $e_{V, \mathrm{CO}_{2}}^{t}$ is higher for close boundaries.

(3) In Fig. 12d, the injection efficiency pattern remains the same as for previous examples by changing the production $P_{\mathrm{bh}}$.

(4) In Fig. 12e the profiles of geothermal heat recovery factor show an increase in energy recovery by decreasing the production $P_{\text {bh }}$ and allowing more fluid production. The interesting result here is that even for the case that $\mathrm{CO}_{2}$ has returned to the production wells $\left(P_{\mathrm{bh}}=180\right.$ bar and $\left.P_{\mathrm{bh}}=160 \mathrm{bar}\right)$, the close system leads to higher recovery factors. The discrepancy between open and close systems for $P_{\mathrm{bh}}=160$ is the least, showing that more fluid production may finally offset the negative effects of open boundaries on heat production. Overall, in all the simulations performed by the $3 \times 3$ well pattern, the close boundaries are more favourable to mine heat from the subsurface system, since brine has no paths except for production. This may be counter-intuitive. However, the model under study is bounded from top and base by thermally insulating units, and the timescale of simulation cannot incorporate the onset and positive feedback of thermal density-driven 
convection that is normally in matter of 100 years (Ennis-King and Paterson 2005; Plaksina and White 2016). Therefore, the open boundaries have served only as escape paths for fluids and reduced the heat and fluid production.

(5) Finally Fig. 12f shows no effects of varying production $P_{\mathrm{bh}}$ on the maximum solid precipitation.

\section{Conclusions and Future Considerations}

The communication or lack of hydrologic communication of a geothermal system with its surrounding aquifer has profound effects on performance of integrated $\mathrm{CO}_{2}$ sequestration-heat recovery operations, especially if the budget of the operation can be exhausted by large number of operating injection/production wells. If the aquifer is compartmentalised by sealing faults so that boundaries could be assumed as fully close, injecting $\mathrm{CO}_{2}$ can help to produce the pressure required for fluid production by generating a steep pressure gradient between injection and production wells. However, this pressure can build up excessively so that pressure management will be required either by reducing the injection rate throughout the injection operation or allowing more fluid extraction by lowering the minimum operational production bottomhole pressure. For the same system of close boundaries, while the fluid production impacts positively the performance of heat production from the system, it leads to negative impact on the synergistically intended carbon sequestration side of the project by back-producing $\mathrm{CO}_{2}$ from production wells. Therefore between objectives of the operation, there is a conflict. If the system under operation is diagnosed to possess hydrologically open boundaries with unhindered flow, heat and pressure communications with the surrounding, the fate of operation with large well spacing depends strongly on minimum operational production bottomhole pressure. In this case, one must calculate the direction of pressure gradient. If the gradient remains largely towards the outside of the geothermal system for large part of the operation, it means that the fluid will be pushed outside which benefits the operation in terms of additional $\mathrm{CO}_{2}$ storage injectivity, efficiency and net cumulative amounts. However, against this benefit, the geothermal heat recovery is undermined, as there is a sharp decrease in hot resident fluid production. If the pressure gradient is towards the inside of the geothermal system, i.e. the operation is underpressurising the system, in expense of adversely affected $\mathrm{CO}_{2}$ storage efficiency and injectivity, the fluid production is enhanced and the relative heat recovery loss compared to close boundaries is offset.

Above-mentioned discrepancies between open and close systems disappear when the number of wells is increased and the well spacing becomes smaller, albeit with additional cost of drilling more wells. An engineering cost-effective trade-off analysis is then required to make judicious decisions as to how many wells can be drilled in an area of a geothermal system, so that the effects of boundaries (or uncertainty in them) are minimised.

The conclusions above are based on over-simplifying aquifer representation. Although it was tried to make the hot sedimentary aquifer under study as representative as possible (for example a computationally heavy 3D model rather than $2 \mathrm{D}$ was consider), realistically there are complexities in terms of

- Heterogeneity in porosity, permeability, net to gross

- Conductive heat flux

- Dynamic time-dependent water influx from boundaries and large-scale groundwater stream flows. 
Above-mentioned factors should be included in future research works. For example, heterogeneity will impact storage efficiency and heat recovery factor. However, the interplay of heterogeneity and system boundaries is a matter of investigation. Additionally for an EGS system with carbon sequestration as an ancillary objective, the effect of boundaries may elucidate interesting deductions: if the flow paths through man-made fractures have extended beyond targeted zone, or they remain fully inside the targeted zone so that no flow leakages occur across the boundaries.

Acknowledgements Thanks are due to the University of Manchester, Faculty of Engineering and Science to financially support the author to acquire a HP ProLiant Server and ECLIPSE Schlumberger's licence essential for conducting the presented research. The author appreciates the constructive comments of three anonymous reviewers of this paper.

Open Access This article is distributed under the terms of the Creative Commons Attribution 4.0 International License (http://creativecommons.org/licenses/by/4.0/), which permits unrestricted use, distribution, and reproduction in any medium, provided you give appropriate credit to the original author(s) and the source, provide a link to the Creative Commons license, and indicate if changes were made.

\section{Appendix A}

\section{Density and Viscosity of Brine in Presence of $\mathrm{CO}_{2}, \mathrm{NaCl}$ and $\mathrm{CaCl}_{2}$}

The gas density is obtained by modified Redlich-Kwong equation, and the gas viscosity is calculated from Vesovic et al. (1990) and Fenghour et al. (1998), whereas for brine, the density and viscosity are first calculated for pure water by an analytical form as detailed by IAPWS (1997), denoted by $\rho_{0}(p, T)$ and $\mu_{0}(p, T)$, respectively. Then the Ezrokhi's method is applied to calculate the effect of salt and $\mathrm{CO}_{2}$ (Zaytsev and Aseyev 1993):

$$
\begin{aligned}
& \rho=\rho_{0}(p, T) \exp \left[\sum_{c=1}^{N_{c}}\left(\alpha_{0, c}+\alpha_{1, c} T+\alpha_{2, c} T^{2}\right) W_{c}\right] \\
& \mu=\mu_{0}(p, T) \exp \left[\sum_{c=1}^{N_{c}}\left(\beta_{0, c}+\beta_{1, c} T+\beta_{2, c} T^{2}\right) W_{c}\right]
\end{aligned}
$$

where $W_{c}$ is the weight fraction of the non-water component $c, T$ is the temperature in ${ }^{\circ} \mathrm{C}$, and $\alpha_{[0,1,2], c}$ and $\beta_{[0,1,2], c}$ are constants for component $i$ reported in Table 3.

Table 3 The Ezrokhi's method temperature coefficients for density correction. (Reproduced with permission from Zaytsev and Aseyev 1993)

\begin{tabular}{lllllll}
\hline Component $c$ & $\alpha_{0, c}$ & $\beta_{0, c}$ & $\alpha_{1, c}$ & $\beta_{1, c}$ & $\alpha_{2, c}$ & $\beta_{2, c}$ \\
\hline $\mathrm{CO}_{2}$ & 0.1033 & 0 & $-2.3 \times 10^{-5}$ & 0 & $-2 \times 10^{-6}$ & 0 \\
$\mathrm{NaCl}$ & 0.30936 & 0.718 & $-6.9 \times 10^{-5}$ & 0.00359 & 0 & 0 \\
$\mathrm{CaCl}_{2}$ & 0.3627 & 1.487 & 0 & -0.00172 & 0 & 0 \\
\hline
\end{tabular}


Table 4 Solid component density calculation parameters

\begin{tabular}{llllll}
\hline Component $c$ & $\rho_{c}^{\text {ref }}\left(\mathrm{kg} / \mathrm{m}^{3}\right)$ & $T_{c}^{\text {ref }}\left({ }^{\circ} \mathrm{C}\right)$ & $p_{c}^{\text {ref }}(\mathrm{bar})$ & $c_{P c}(1 / \mathrm{bar})$ & $c_{T c}(1 / \mathrm{K})$ \\
\hline $\mathrm{NaCl}$ & 2170 & 15.56 & 1.01325 & 0 & 0 \\
$\mathrm{CaCl}_{2}$ & 2150 & 15.56 & 1.01325 & 0 & 0 \\
\hline
\end{tabular}

For $\rho_{c}^{\text {ref }}$ the default values in ECLIPSE E300 CO2STORE option (Schlumberger 2014a) have been used. In the absence of date, $c_{P c}$ and $c_{T c}$ are set equal to zero

\section{Density of Solid Phase}

The solid molar density $\left(\mathrm{kg} \mathrm{mol} / \mathrm{m}^{3}\right)$ is calculated by analogy to ideal solutions as

$$
b_{\mathrm{s}}=\frac{1}{\sum_{c=1}^{N_{c}}\left[\frac{s_{c} M_{c}}{\rho_{c}^{\mathrm{ref}}}\left(1-c_{P c}\left(p-p_{c}^{\mathrm{ref}}\right)\right)\left(1-c_{T c}\left(T-T_{c}^{\mathrm{ref}}\right)\right)\right]}
$$

where $s_{c}$ is the mole fraction of component $c$ in the solid phase, $M_{c}$ is the molecular weight of component $c, \rho_{c}^{\mathrm{ref}}, p_{c}^{\mathrm{ref}}$ and $T_{c}^{\mathrm{ref}}$ are the component reference density, pressure and temperature, respectively, and $c_{P c}$ and $c_{T c}$ are the component solid compressibility and thermal expansion coefficient, respectively. For $\mathrm{NaCl}$ and $\mathrm{CaCl}_{2}$ I use the constants reported in Table 4 .

\section{Adsorption of Salt and Permeability Modification}

For the adsorption of solid phase, I use the Langmuir isotherm model by assuming that the rate of solid absorption, $\dot{r}_{\mathrm{ad}}(\mathrm{kg} / \mathrm{s})$, is the same as the rate of solid desorption, $\dot{r}_{\mathrm{d}}(\mathrm{kg} / \mathrm{s})$. The adsorption rate is related to the adsorption rate coefficient, $\kappa_{\mathrm{ad}}\left(\mathrm{m}^{3} / \mathrm{s}\right)$, the maximum adsorbed concentration $C_{\mathrm{ad}}^{\max }(\mathrm{kg} / \mathrm{kg})$, the adsorbed concentration, $C_{\mathrm{ad}}(\mathrm{kg} / \mathrm{kg})$ and the suspended solution solid concentration, $C_{\mathrm{s}}\left(\mathrm{kg} / \mathrm{m}^{3}\right)$ :

$$
\dot{r}_{\mathrm{ad}}=\kappa_{\mathrm{ad}} C_{\mathrm{s}}\left(C_{\mathrm{ad}}^{\max }-C_{\mathrm{ad}}\right)
$$

The desorption rate is related to the adsorbed concentration and the desorption constant, $\kappa_{\mathrm{de}}(\mathrm{kg} / \mathrm{s})$ :

$$
\dot{r}_{\mathrm{d}}=\kappa_{\mathrm{d}} C_{\mathrm{ad}},
$$

By equating Eqs. (A3) and (A4) and using $\kappa=\kappa_{\mathrm{ad}} / \kappa_{\mathrm{d}}\left(\mathrm{m}^{3} / \mathrm{kg}\right)$, one can write:

$$
C_{\mathrm{ad}}=\frac{\kappa C_{\mathrm{s}}}{1+\kappa C_{\mathrm{s}}} C_{\mathrm{ad}}^{\max }
$$

I use $C_{\text {ad }}^{\max }=0.01 \mathrm{~kg} / \mathrm{kg}$ and $\kappa=20 \mathrm{~m}^{3} / \mathrm{kg}$ in the model. These values are assigned here based on the Schlumberger (2014a) examples for Langmuir isotherm model but are subject to experimental measurement.

When solid adsorbs to the rock, the porosity reduces. If the original pore space is denoted by $V_{\mathrm{p}}$ with the porosity of $\phi_{0}$, after precipitation the pore space available for fluid is denoted by $V_{\mathrm{f}}$ with porosity of $\phi$, and the pore space taken by solid is denoted by $V_{\mathrm{s}}$. I can write $V_{\mathrm{p}}=V_{\mathrm{f}}+V_{\mathrm{s}}=V_{\mathrm{p}}\left(v_{\mathrm{f}}+v_{\mathrm{s}}\right)$, where $v_{\mathrm{f}}=V_{\mathrm{f}} / V_{\mathrm{p}}=\phi / \phi_{0}$ and $v_{\mathrm{s}}=V_{\mathrm{s}} / V_{\mathrm{p}}$ are the fraction volumes of fluid and solid phases. For the fluid phase, I can write $v_{\mathrm{f}}=v_{\mathrm{g}}+v_{\mathrm{w}}=v_{\mathrm{f}}\left(S_{\mathrm{g}}+S_{\mathrm{w}}\right)$. Denoting $v_{\mathrm{s}}=\hat{S}_{\mathrm{s}}=1-\phi / \phi_{0}$, for fluid phase $v_{\mathrm{g}}=S_{\mathrm{g}} v_{\mathrm{f}}=S_{\mathrm{g}}\left(1-\hat{S}_{\mathrm{s}}\right)=\hat{S}_{\mathrm{g}}$ and $v_{\mathrm{w}}=S_{\mathrm{w}} v_{\mathrm{f}}=S_{\mathrm{w}}\left(1-\hat{S}_{\mathrm{s}}\right)=\hat{S}_{\mathrm{w}}$. In this way, $\hat{S}_{\mathrm{g}}$ and $\hat{S}_{\mathrm{W}}$ are the normalised gas and water 
saturations due to presence of solid, respectively. The sum of $\hat{S}_{\mathrm{s}}, \hat{S}_{\mathrm{g}}$ and $\hat{S}_{\mathrm{w}}$ is equal to 1 . Porosity reduction, in turn, impacts formation permeability. I use Kozeny-Carman grain model to calculate changes in permeability due to changes in porosity (Bolton et al. 1999):

$$
\frac{k}{k_{0}}=\left(\frac{\phi}{\phi_{0}}\right)^{3}\left(\frac{1-\phi_{0}}{1-\phi}\right)^{2}
$$

where $\phi_{0}$ and $k_{0}$ are the initial porosity and permeability. Replacing $\hat{S}_{\mathrm{s}}=1-\phi / \phi_{0}$ :

$$
\frac{k}{k_{0}}=\frac{\left(1-\hat{S}_{\mathrm{s}}\right)^{3}}{\left(1+\left(\phi_{0} /\left(1-\phi_{0}\right)\right) \hat{S}_{\mathrm{s}}\right)^{2}}
$$

I implement the variations in permeability dynamically in the simulations. The creditability of this equation is limited to homogeneous porous media. However, for real reservoirs, the relation of permeability and porosity can be different (see, e.g. Mostaghimi et al. 2016).

\section{Heat Capacity in Presence of Solid Phase}

ECLIPSE E300 (Schlumberger 2014b) has built-in equations for phase heat capacities in $\mathrm{kJ} / \mathrm{kg} \mathrm{mol:}$

$$
\begin{aligned}
h_{\mathrm{g}}= & \sum_{c=1}^{N_{c}} y_{c} M_{c}\left[C_{p 1, \mathrm{~g}, c}\left(T-T^{\mathrm{sc}}\right)+0.5 \times C_{p 2, \mathrm{~g}, c}\left(T-T^{\mathrm{sc}}\right)^{2}\right] \\
h_{\mathrm{w}}= & \sum_{c=1}^{N_{c}} a_{c} M_{c}\left[C_{p 1, \mathrm{w}, c}\left(T-T^{\mathrm{sc}}\right)+0.5 \times C_{p 2, \mathrm{w}, c}\left(T-T^{\mathrm{sc}}\right)^{2}\right] \\
h_{\mathrm{s}}= & \sum_{c=1}^{N_{c}} s_{c} M_{c}\left[C_{p 1, \mathrm{~s}, c}\left(T-T^{\mathrm{sc}}\right)+0.5 \times C_{p 2, \mathrm{~s}, c}\left(T-T^{\mathrm{sc}}\right)^{2}\right]
\end{aligned}
$$

where $y_{c}, a_{c}$ and $s_{c}$ are the gas phase, aqueous phase and solid phase mole fraction of component $c$, respectively. In these equations, $C_{p 1, \mathrm{~g}, c}, C_{p 1, \mathrm{w}, c}$ and $C_{p 1, \mathrm{~s}, c}(\mathrm{~kJ} / \mathrm{kg} / \mathrm{K})$ are the first, and $C_{p 2, \mathrm{~g}, c}, C_{p 2, \mathrm{w}, c}$ and $C_{p 2, \mathrm{~s}, c}\left(\mathrm{~kJ} / \mathrm{kg} / \mathrm{K}^{2}\right)$ are the second coefficients of the component specific heats in the gaseous, aqueous and solid phases, respectively. These equations disregard the energy of mixing, so that the heat capacity of each phase is the sum of components heat capacities. The molar heat capacity of pure $\mathrm{CO}_{2}$ and pure water is given by Perry and Green, (1999):

$$
\begin{gathered}
h_{\mathrm{g}}^{\prime}=45.369+8.6881 \times 10^{-3} T-961,930 \times 10^{-3} T^{2}, \\
h_{\mathrm{w}}^{\prime}=276.37-2.0901 \times T+8.125 \times 10^{-3} T^{2}-0.014116 \times 10^{-3} T^{3}+9.3701 \times 10^{-9} T^{4},
\end{gathered}
$$

where $h_{\mathrm{g}}$ and $h_{\mathrm{w}}$ are in $\mathrm{kJ} / \mathrm{kg}$ mol and $T$ is in Kelvin. In order to obtain the coefficients of Eqs. (A8a-A8c) I equate $h_{\mathrm{g}}=h_{\mathrm{g}}^{\prime}$ and $h_{\mathrm{w}}=h_{\mathrm{w}}^{\prime}$ for gaseous phase with pure $\mathrm{CO}_{2}$ and aqueous phase with pure $\mathrm{H}_{2} \mathrm{O}$, using $T^{\mathrm{SC}}=15.56{ }^{\circ} \mathrm{C}$ and $T=60-250{ }^{\circ} \mathrm{C}$. I obtained $C_{p 1, \mathrm{~g}, \mathrm{CO}_{2}}=0.22 \mathrm{~kJ} / \mathrm{kg} / \mathrm{K}, C_{p 2, \mathrm{~g}, \mathrm{CO}_{2}}=0.004 \mathrm{~kJ} / \mathrm{kg} / \mathrm{K}^{2}, C_{p 1, \mathrm{w}, \mathrm{H}_{2} \mathrm{O}}=2.6 \mathrm{~kJ} / \mathrm{kg} / \mathrm{K}$, and $C_{p 2, \mathrm{w}, \mathrm{H}_{2} \mathrm{O}}=0.01 \mathrm{~kJ} / \mathrm{kg} / \mathrm{K}^{2}$. I use the same coefficients for aqueous $\mathrm{CO}_{2}$ and vapour as obtained above. For $\mathrm{NaCl}$ and $\mathrm{CaCl}_{2}$ (that can exist in solid and aqueous phases), I use the coefficients reported in Table 5. 
Table 5 Coefficients of the components heat capacity

\begin{tabular}{lllllll}
\hline Component $c$ & $\begin{array}{l}C_{p 1, \mathrm{~g}, c} \\
(\mathrm{~kJ} / \mathrm{kg} / \mathrm{K})\end{array}$ & $\begin{array}{l}C_{p 1, \mathrm{w}, c} \\
(\mathrm{~kJ} / \mathrm{kg} / \mathrm{K})\end{array}$ & $\begin{array}{l}C_{p 1, \mathrm{~s}, c} \\
(\mathrm{~kJ} / \mathrm{kg} / \mathrm{K})\end{array}$ & $\begin{array}{l}C_{p 2, \mathrm{~g}, c} \\
\left(\mathrm{~kJ} / \mathrm{kg} / \mathrm{K}^{2}\right)\end{array}$ & $\begin{array}{l}C_{p 2, \mathrm{w}, c} \\
\left(\mathrm{~kJ} / \mathrm{kg} / \mathrm{K}^{2}\right)\end{array}$ & $\begin{array}{l}C_{p 2, \mathrm{~s}, c} \\
\left(\mathrm{~kJ} / \mathrm{kg} / \mathrm{K}^{2}\right)\end{array}$ \\
\hline $\mathrm{CO}_{2}$ & 0.22 & 0.22 & - & 0.004 & 0.004 & - \\
$\mathrm{H}_{2} \mathrm{O}$ & 2.6 & 2.6 & - & 0.01 & 0.01 & - \\
$\mathrm{NaCl}$ & - & 0.5 & 0.5 & - & 0.001 & 0.001 \\
$\mathrm{CaCl}_{2}$ & - & 0.5 & 0.5 & - & 0.001 & 0.001 \\
\hline
\end{tabular}

The values are extracted from CO2STORE THERMAL example in the ECLISPE E300 dataset (Supplementary Information)

\section{Governing Equations}

ECLISPE E300 solves a coupled problem integrating (1) the component conservation equation for each fluid component in each gridblock at each timestep (leading to the nonlinear residual $R_{\mathrm{fl}}$ ), (2) the energy conservation equation in each gridblock at each timestep (leading to the nonlinear residual $R_{\mathrm{e}}$ ) and (3) the conservation of volume in each gridblock at each timestep (leading to the nonlinear residual $R_{\mathrm{V}}$ ) using a Fully Implicit Scheme (Schlumberger 2014a):

$$
\begin{gathered}
R_{\mathrm{fl}}=\frac{\mathrm{d}}{\mathrm{d} t}\left(V_{\mathrm{p}} m_{\mathrm{fl}}\right)+F_{\mathrm{fl}}+Q_{\mathrm{fl}}=0 \\
R_{\mathrm{e}}=\frac{\mathrm{d}}{\mathrm{d} t}\left(V_{\mathrm{b}} e\right)+F_{\mathrm{e}}+C_{\mathrm{e}}+Q_{\mathrm{HL}}+Q_{\mathrm{e}}=0 \\
R_{\mathrm{v}}=V_{\mathrm{p}}-V_{\mathrm{f}}=0
\end{gathered}
$$

where $V_{\mathrm{p}}$ is the pore volume, $F_{\mathrm{fl}}$ is the net flow rate into neighbouring gridblocks, $Q_{\mathrm{fl}}$ is the net flow rate into wells during the timestep, $V_{\mathrm{b}}$ is the bulk volume, $F_{\mathrm{e}}$ is the convective enthalpy flow rate into neighbouring gridblocks, $C_{\mathrm{e}}$ is the conductive energy flow rate into neighbouring gridblocks, $Q_{\mathrm{HL}}$ is the conductive energy flow rate to the surrounding rocks (heat loss), $Q_{\mathrm{e}}$ is the net enthalpy flow rate into wells during the timestep, and $V_{\mathrm{f}}$ is the fluid volume (Schlumberger 2014a).

\section{Appendix B}

In case of the $3 \times 3$ well pattern with in close system, the storage capacity may be significantly limited due to the observed rapid pressure build-up. For the safe and secure long-term $\mathrm{CO}_{2}$ injection, it is imperative to consider the risks of increased pressure. In order to control the reservoir pressure, the injection rate can be limited by the fracture pressure of the reservoir based on the current practice for underground injection control of liquid wastes (USEPA 1994; Zhou et al. 2008). The regulatory standard controls the injection of $\mathrm{CO}_{2}$ so that the maximum injection pressure $\left(P_{\mathrm{bh}}\right)$ does not exceed the measured formation fracture pressure. In the literature, there are specific thresholds of this constraint, such as $50 \%$ of the initial hydrostatic pressure allowable increase (Zhou et al. 2008) or $90 \%$ of fracture pressure as the maximum recommended by the Interstate Oil and Gas Compact Commission (IOGCC 2007). Although this value is site specific, in this work, I use the latter:

$$
p_{\mathrm{w}}^{t} \leq 0.9 p_{\mathrm{fr}, \mathrm{w}}
$$


where $p_{\mathrm{w}}^{t}$ is the $P_{\mathrm{bh}}$ of injection well, $w$, at time $t$ calculated at the reference depth of $2000 \mathrm{~m}$, and $p_{\mathrm{fr}, \mathrm{w}}$ is the fracture pressure of injection well, $w$, at top depth of the perforations $(2000 \mathrm{~m})$. There are various values for suggested fracture pressure limits in the literature, and the allowable maximum pressure increase has to be assessed on a case-by-case basis (Thibeau and Mucha 2011); however, I present a simplistic approach where the fracture pressure is calculated by $p_{\mathrm{fr}, \mathrm{w}}=\left(g_{\mathrm{f}} / g_{\mathrm{h}}\right) p_{\mathrm{h}, i}^{t_{0}}$. Here, $g_{\mathrm{f}}$ and $g_{\mathrm{h}}$ are, respectively, the fracture gradient and the hydrostatic gradient of the geothermal system, and $p_{\mathrm{h}, i}^{t 0}$ is the initial hydrostatic pressure at gridblock $i$ where the well $w$ is perforated. Assuming the fracture gradient is in the range of the typical North Sea reservoirs and is equal to $0.226 \mathrm{bar} / \mathrm{m}$ (Cawley et al. 2005), and the hydrostatic gradient is $0.102 \mathrm{bar} / \mathrm{m}$ similar to the Forties Reservoir in the North Sea [the initial pressure of Forties is 222 bar at $2175 \mathrm{~m}$ (Wills 1991)], the pressure constraint can be written as:

$$
p_{\mathrm{w}}^{t} \leq 1.99 p_{\mathrm{h}, i}^{t_{0}}
$$

By visiting Fig. 6 for injection $P_{\text {bh }}$ profiles of the middle injection well for various simulations, and considering $p_{\mathrm{h}, i}^{t_{0}}=200 \mathrm{bar}, p_{\mathrm{w}}^{t} \leq 400 \mathrm{bar}$, even the injection with $Q=4.5 \times 10^{6}$ $\mathrm{sm}^{3} /$ day, for the $3 \times 3$ well pattern in close system is not exceeding the limit. However, administering higher injection rates in the $3 \times 3$ well pattern in close system will lead to violation of Eq. (B2).

\section{Appendix C}

In this Appendix, the sensitivity of results to the grid resolution is discussed. A finer scale resolution model of $50 \times 50 \times 10=225,000$ gridblocks (each grid $20 \mathrm{~m} \times 20 \mathrm{~m} \times 10 \mathrm{~m}$ ) is compared with the original coarse scale model of $60 \times 60 \times 10=36,000$ gridblocks $(50 \mathrm{~m} \times 50 \mathrm{~m} \times 10 \mathrm{~m})$. In the comparison, the $3 \times 3$ well pattern, in close system, with $Q=1.5 \times 10^{6} \mathrm{sm}^{3} /$ day is used. All the performance metrics are calculated using these two simulation runs and are presented in Fig. 13. It is evident from the figure the metrics are sensitive to the grid resolution. The maximum saturation of salt $\left[\max \left(\hat{S}_{\mathrm{s}}\right)\right]$ is extremely sensitive to the grid resolution because the volume of gridblocks is reduced in the fine scale, and therefore, higher saturations are achieved by fine grid resolutions. Other outputs-while also sensitive to the grid resolution-follow the same pattern and trend, but is evident that the coarse scale simulations overestimate $M_{\text {net }}^{t}, e_{\text {inj }}^{t}, e_{V, \mathrm{CO}_{2}}^{t}$ and $r_{\mathrm{g}}^{t}$. The interplay of performance metrics for different well layouts with the grid resolution will be taken care of in an ensuing publication. 

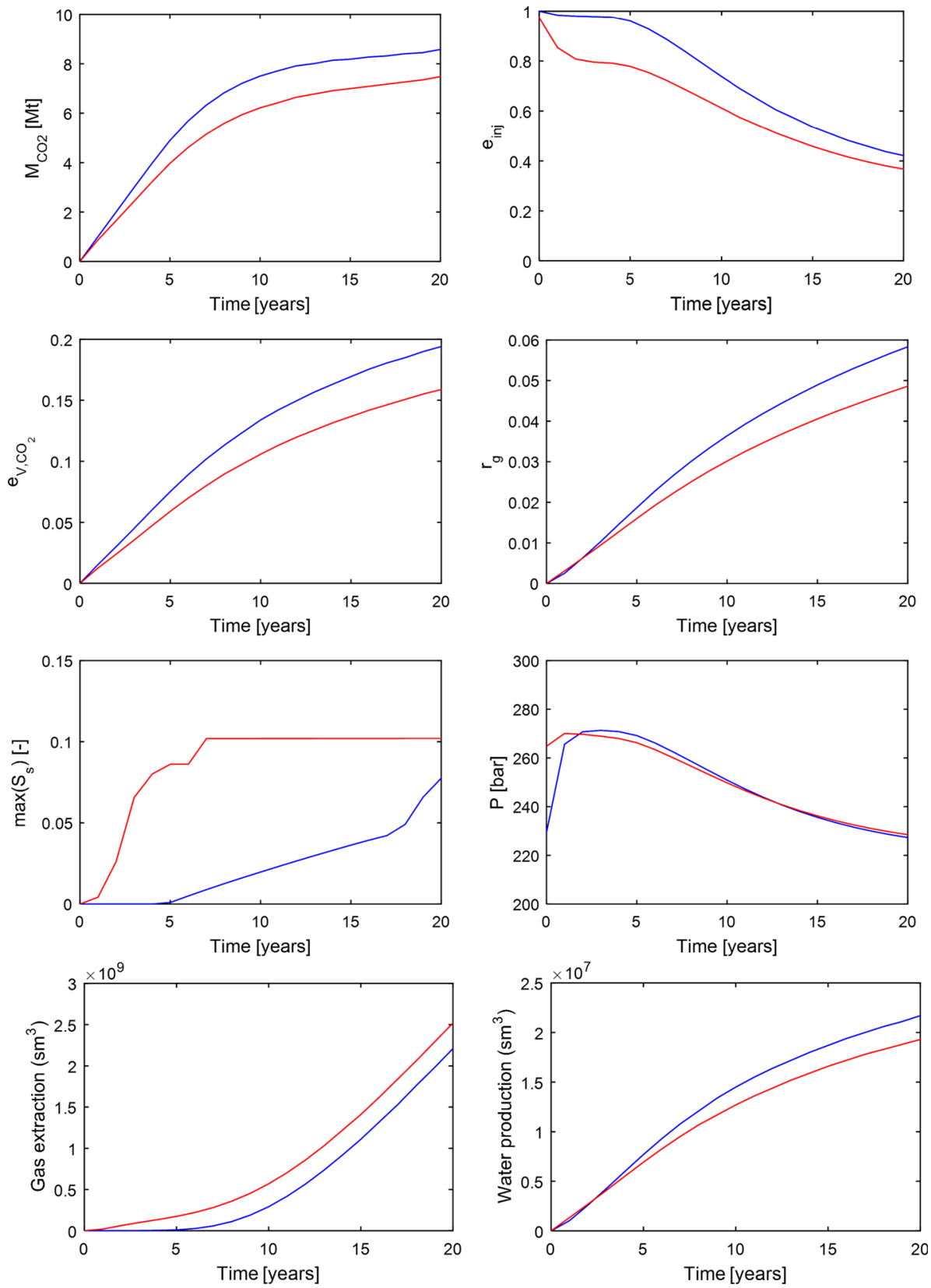

Fig. 13 The comparison of different output metrics for the coarse scale model (blue) and the fine scale model (red)

\section{References}

Adams, B.M., Kuehn, T.H., Bielicki, J.M., Randolph, J.B., Saar, M.O.: On the importance of the thermosiphon effect in CPG $\left(\mathrm{CO}_{2}\right.$ plume geothermal) power systems. Energy 69, 409-418 (2014) 
Atrens, A.D., Gurgenci, H., Rudolph, V.: $\mathrm{CO}_{2}$ thermosiphon for competitive geothermal power generation. Energy Fuels 23(1), 553-557 (2008)

Babaei, M., Pan, I., Alkhatib, A.: Robust optimization of well location to enhance hysteretical trapping of $\mathrm{CO}_{2}$ : assessment of various uncertainty quantification methods and utilization of mixed response surface surrogates. Water Resour. Res. 51(12), 9402-9424 (2015)

Bachu, S.: Review of $\mathrm{CO}_{2}$ storage efficiency in deep saline aquifers. Int. J. Greenh. Gas Control 40, 188-202 (2015)

Birkholzer, J.T., Oldenburg, C.M., Zhou, Q.: $\mathrm{CO}_{2}$ migration and pressure evolution in deep saline aquifers. Int. J. Greenh. Gas Control 40, 203-220 (2015)

Bolton, E.W., Lasaga, A.C., Rye, D.M.: Long-term flow/chemistry feedback in a porous medium with heterogenous permeability; kinetic control of dissolution and precipitation. Am. J. Sci. 299(1), 1-68 (1999)

Bonté, D., Van Wees, J.-D., Verweij, J.M.: Subsurface temperature of the onshore Netherlands: new temperature dataset and modelling. Neth. J. Geosci. 91(04), 491-515 (2012)

Borgia, A., Pruess, K., Kneafsey, T.J., Oldenburg, C.M., Pan, L.: Numerical simulation of salt precipitation in the fractures of a $\mathrm{CO}_{2}$-enhanced geothermal system. Geothermics 44, 13-22 (2012)

Brown, D.W.: A hot dry rock geothermal energy concept utilizing supercritical $\mathrm{CO}_{2}$ instead of water. In: Proceedings of Twenty-Fifth Workshop on Geothermal Reservoir Engineering Stanford University, Stanford, California, 24-26 Jan 2000, pp. 233-238 (2000)

Buscheck, T.A., Chen, M., Sun, Y., Hao, Y., Elliot, T.R.: Two-stage, integrated, geothermal- $\mathrm{CO}_{2}$ storage reservoirs: An approach for sustainable energy production, $\mathrm{CO}_{2}$-sequestration security, and reduced environmental risk. Lawrence Livermore National Laboratory under Contract DE-AC52-07NA27344 (2012a)

Buscheck, T.A., Elliot, T.R., Celia, M.A., Chen, M., Hao, Y., Lu, C., Sun, Y.: Integrated, geothermal-CO $\mathrm{CO}_{2}$ storage reservoirs: adaptable, multi-stage, sustainable, energy-recovery strategies that reduce carbon intensity and environmental risk. In: Geothermal Resources Council, vol. 30 (2012b)

Cameron, D.A., Durlofsky, L.J.: Optimization of well placement, $\mathrm{CO}_{2}$ injection rates, and brine cycling for geological carbon sequestration. Int. J. Greenh. Gas Control 10, 100-112 (2012)

Cawley, S.J., Saunders, M.R., Le Gallo, Y., Carpentier, B., Holloway, S., Kirby, G.A., Bennison, T., Wickens, L., Wikramaratna, R., Bidstrup, T., Arkley, S.L.B., Browne, M.A.E., Ketzer, J.M.: The NGCAS Projectassessing the potential for EOR and $\mathrm{CO}_{2}$ storage at the Forties Oil Field, offshore UK-results from the $\mathrm{CO}_{2}$ capture project, vol 2. In: Geologic Storage of Carbon Dioxide with Monitoring and Verification. SM Benson Elsevier Science, London (2005)

Chen, M., Tompson, A.F.B., Mellors, R.J., Abdalla, O.: An efficient optimization of well placement and control for a geothermal prospect under geological uncertainty. Appl. Energy 137, 352-363 (2015)

Cihan, A., Birkholzer, J.T., Bianchi, M.: Optimal well placement and brine extraction for pressure management during $\mathrm{CO}_{2}$ sequestration. Int. J. Greenh. Gas Control 42, 175-187 (2015)

Crooijmans, R.A., Willems, C.J.L., Nick, H.M., Bruhn, D.F.: The influence of facies heterogeneity on the doublet performance in low-enthalpy geothermal sedimentary reservoirs. Geothermics 64, 209-219 (2016)

DiPippo, R.: Geothermal Power Plants: Principles, Applications, Case Studies and Environmental Impact. Butterworth-Heinemann, Oxford (2012)

Ennis-King, J., Paterson, L.: Role of convective mixing in the long-term storage of carbon dioxide in deep saline formations. SPE J. 10(3), 349-356 (2005)

Fenghour, A., Wakeham, W.A., Vesovic, V.: The viscosity of carbon dioxide. J. Phys. Chem. Ref. Data 27, 31 (1998)

Fouillac, C., Sanjuan, B., Gentier, S., Czernichowski-Lauriol, I.: Could sequestration of $\mathrm{CO}_{2}$ be combined with the development of enhanced geothermal systems. In: Third Annual Conference on Carbon Capture and Sequestration, Alexandria, VA (2004)

Franco, A., Vaccaro, M.: Numerical simulation of geothermal reservoirs for the sustainable design of energy plants: a review. Renew. Sustain. Energy Rev. 30(C), 987-1002 (2014)

Ganjdanesh, R., Pope, G.A., Sepehrnoori, K.: Production of energy from saline aquifers: a method to offset the energy cost of carbon capture and storage. Int. J. Greenh. Gas Control 34, 97-105 (2015)

Guyant, E., Han, W.S., Kim, K.-Y., Park, M.-H., Kim, B.-Y.: Salt precipitation and $\mathrm{CO}_{2}$ /brine flow distribution under different injection well completions. Int. J. Greenh. Gas Control 37, 299-310 (2015)

Heath, J.E., McKenna, S.A., Dewers, T.A., Roach, J.D., Kobos, P.H.: Multiwell $\mathrm{CO}_{2}$ injectivity: impact of boundary conditions and brine extraction on geologic $\mathrm{CO}_{2}$ storage efficiency and pressure buildup. Environ. Sci. Technol. 48(2), 1067-1074 (2014)

Holloway, S.: Storage capacity and containment issues for carbon dioxide capture and geological storage on the UK continental shelf. Proc. Inst. Mech. Eng. Part A J. Power Energy 223(3), 239-248 (2009)

IAPWS: Release on the IAPWS industrial formulation 1997 for the thermodynamic properties of water and steam. In: IAPWS Secretariat. Electric Power Research Institute, Palo Alto, CA (1997) 
IOGCC: Storage of carbon dioxide in geologic structures: a legal and regulatory guide for states and provinces (2007)

McNamara, D.D., Sewell, S., Buscarlet, E., Wallis, I.C.: A review of the Rotokawa geothermal field, New Zealand. Geothermics 59, 281-293 (2016)

Mostaghimi, P., Liu, M., Arns, C.H.: Numerical simulation of reactive transport on micro-CT images. Math. Geosci. 48.8(2016), 963-983 (2016)

Perry, R.H., Green, D.W.: Perry's Chemical Engineers' Handbook. McGraw-Hill Professional, New York (1999)

Plaksina, T., White, C.: Modeling coupled convection and carbon dioxide injection for improved heat harvesting in geopressured geothermal reservoirs. Geotherm. Energy 4(1), 1 (2016)

Pruess, K.: Enhanced geothermal systems (EGS) using $\mathrm{CO}_{2}$ as working fluid-a novel approach for generating renewable energy with simultaneous sequestration of carbon. Geothermics 35(4), 351-367 (2006)

Pruess, K., Azaroual, M.: On the feasibility of using supercritical $\mathrm{CO}_{2}$ as heat transmission fluid in an engineered hot dry rock geothermal system. In: The Thirty-First Workshop on Geothermal Reservoir Engineering Stanford University, Stanford, California, 30 Jan-1 Feb 2006, SGP-TR-179 (2006)

Pruess, K., Müller, N.: Formation dry-out from $\mathrm{CO}_{2}$ injection into saline aquifers: 1. Effects of solids precipitation and their mitigation. Water Resour. Res. 45(3), W03402 (2009). https://doi.org/10.1029/ 2008WR007101

Randolph, J.B., Saar, M.O.: Combining geothermal energy capture with geologic carbon dioxide sequestration. Geophys. Res. Lett. 38(10), L10401 (2011a)

Randolph, J.B., Saar, M.O.: Coupling carbon dioxide sequestration with geothermal energy capture in naturally permeable, porous geologic formations: implications for $\mathrm{CO}_{2}$ sequestration. Energy Procedia 4 , 2206-2213 (2011b)

Saeid, S., Al-Khoury, R., Nick, H.M., Hicks, M.A.: A prototype design model for deep low-enthalpy hydrothermal systems. Renew. Energy 77, 408-422 (2015)

Salimi, H., Wolf, K.-H.: Integration of heat-energy recovery and carbon sequestration. Int. J. Greenh. Gas Control 6, 56-68 (2012)

Schlumberger: ECLIPSE Technical Description v2014.1 (2014a)

Schlumberger: ECLIPSE Reference Manual v2014.1 (2014b)

Spycher, N., Pruess, K.: $\mathrm{CO}_{2}-\mathrm{H}_{2} \mathrm{O}$ mixtures in the geological sequestration of $\mathrm{CO}_{2}$. II. Partitioning in chloride brines at $12-100{ }^{\circ} \mathrm{C}$ and up to 600 bar. Geochim. Cosmochim. Acta 69(13), 3309-3320 (2005)

Spycher, N., Pruess, K.: A phase-partitioning model for $\mathrm{CO}_{2}$-brine mixtures at elevated temperatures and pressures: application to $\mathrm{CO}_{2}$-enhanced geothermal systems. Transp. Porous Media 82(1), 173-196 (2010)

Thibeau, S., Mucha, V.: Have we overestimated saline aquifer $\mathrm{CO}_{2}$ storage capacities? Oil Gas Sci. Technol. 66(1), 81-92 (2011)

Tutolo, B.M., Kong, X.-Z., Seyfried, W.E., Saar, M.O.: High performance reactive transport simulations examining the effects of thermal, hydraulic, and chemical (THC) gradients on fluid injectivity at carbonate CCUS reservoir scales. Int. J. Greenh. Gas Control 39, 285-301 (2015)

USEPA: Determination of Maximum Injection Pressure for Class I Wells, United States Environmental Protection Agency Region 5-Underground Injection Control Section Regional Guidance \#7, edited by EPA, Washington, DC, USA, (1994)

Vesovic, V., Wakeham, W.A., Olchowy, G.A., Sengers, J.V., Watson, J.T.R., Millat, J.: The transport properties of carbon dioxide. J. Phys. Chem. Ref. Data 19, 763 (1990)

Vignaroli, G., Pinton, A., De Benedetti, A.A., Giordano, G., Rossetti, F., Soligo, M., Berardi, G.: Structural compartmentalisation of a geothermal system, the Torre Alfina field (central Italy). Tectonophysics $\mathbf{6 0 8}$, 482-498 (2013)

Vogt, C. (2013), Optimization of geothermal energy reservoir modeling using advanced numerical tools for stochastic parameter estimation and quantifying uncertainties

Vogt, C., Mottaghy, D., Wolf, A., Rath, V., Pechnig, R., Clauser, C.: Reducing temperature uncertainties by stochastic geothermal reservoir modelling. Geophys. J. Int. 181(1), 321-333 (2010)

Wills, J.M.: The Forties Field, Block 21/10, 22/6a, UK North Sea. Geol. Soc. Lond. Mem. 14(1), 301-308 (1991)

Xu, T., Sonnenthal, E., Spycher, N., Pruess, K.: TOUGHREACT - a simulation program for non-isothermal multiphase reactive geochemical transport in variably saturated geologic media: applications to geothermal injectivity and $\mathrm{CO}_{2}$ geological sequestration. Comput. Geosci. 32(2), 145-165 (2006)

$\mathrm{Xu}, \mathrm{T}$. , Pruess, K., Apps, J.: Numerical studies of fluid-rock interactions in enhanced geothermal systems (EGS) with $\mathrm{CO}_{2}$ as working fluid, Report Number: LBNL-63790. In: Proceedings: the 33rd Workshop on Geothermal Reservoir Engineering, Stanford University, Stanford, California, 28-30 Jan (2008) 
Xu, C., Dowd, P.A., Tian, Z.F.: A simplified coupled hydro-thermal model for enhanced geothermal systems. Appl. Energy 140, 135-145 (2015a)

$\mathrm{Xu}$, R., Zhang, L., Zhang, F., Jiang, P.: A review on heat transfer and energy conversion in the enhanced geothermal systems with water/CO $\mathrm{CO}_{2}$ as working fluid. Int. J. Energy Res. 39(13), 1722-1741 (2015b)

Zaytsev, I.D., Aseyev, G.G.: Properties of Aqueous Solutions of Electrolytes. CRC Press, Boca Raton (1993)

Zeidouni, M., Pooladi-Darvish, M., Keith, D.: Analytical solution to evaluate salt precipitation during $\mathrm{CO}_{2}$ injection in saline aquifers. Int. J. Greenh. Gas Control 3(5), 600-611 (2009)

Zhou, Q., Birkholzer, J.T., Tsang, C.-F., Rutqvist, J.: A method for quick assessment of $\mathrm{CO}_{2}$ storage capacity in closed and semi-closed saline formations. Int. J. Greenh. Gas Control 2(4), 626-639 (2008) 